Journal of Educational

and Psychological Sciences

Volume (5), Issue (37): 30 Oct 2021

P: 82 - 98

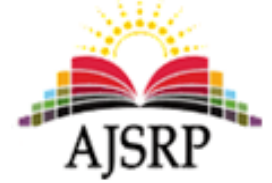

ISSN: 2522-3399
مجلة العلوم

التربوية والنفسية

المجلد (5)، العدد (37): 30 أكتوبر 2021 م

ص: 82 - 98

\title{
The Effect of Using the Learning Cycle Strategy (5E's) on Achievement and Development of Critical Thinking Skills in Science among Eighth Grade Students in Jordan
}

\section{Taghreed S.A Totanji}

Ministry of Education || Jordan

\begin{abstract}
The present study aimed to investigate the effect of using the learning cycle strategy (5E's) on achievement and development of critical thinking skills in science among eighth grade students in Jordan. The study sample consisted of (53) female students who were intentionally selected from two divisions of the eighth grade class at the Al-Jubaiha Secondary School for Girls. 27) A female student, and an educational material was built in the living organisms unit and their environments from the science book for the eighth grade basic in the first semester, and an achievement test was built and a test for critical thinking was used. (5E's) in raising the level of achievement and developing critical thinking skills in science among female students.
\end{abstract}

Keywords: Learning Cycle Strategy (5E's), Critical Thinking Skills, Achievement, the Science, Eighth Grade Students.

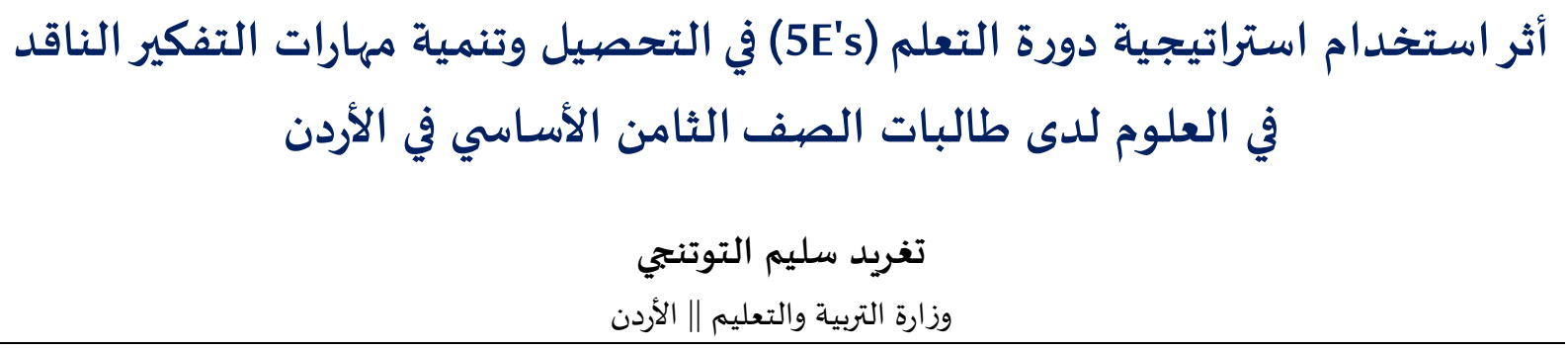

المستخلص: هدفت الدراسة الحالية إلى استقصاء أثر استخدام استراتيجية دورة التعلم (5E's) في التحصيل وتنمية مهارات التفكير الناقد في العلوم لدى طالبات الصف الثامن الأساسي في الأردن، واستخدمت الدراسة المنهج شبه التجريبي، وتكونت عينة الدراسة من (53) طالبة تم اختيارهن بطريقة قصدية من شعبتين من شعب الصف الثامن الأساسي بمدرسة الجبيهة الثانوية للبنات، وقد توزعت ولتهات

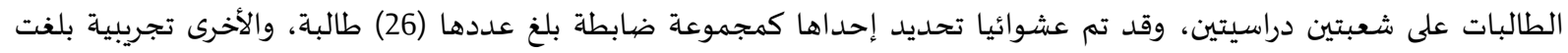

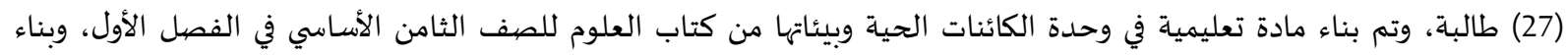

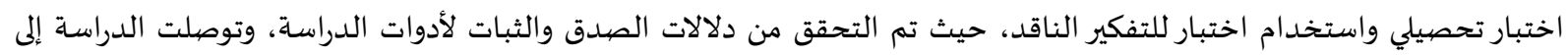

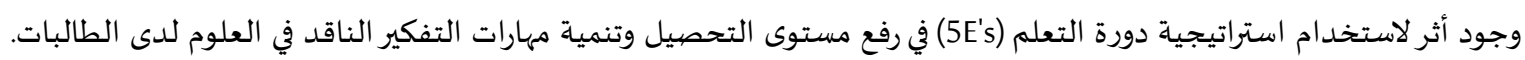
الكلمات المفتاحية: استراتيجية دورة التعلم 5E's، مهارات التفكير الناقد، التحصيل العلوم الصف الثامن الأساسي.

يسهم التعليم بشكل فاعل في تشكيل الأفراد والمجتمعات، وبناء الأفكار، وصناعة الإنسان الذي هو أعظم

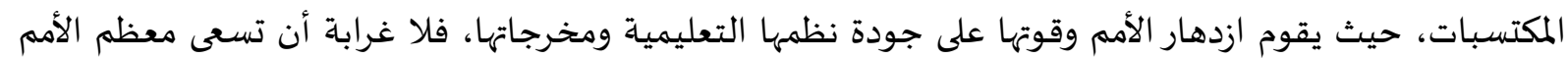
في الدول المتقدمة إلى إصلاح نظمها التعليمية، بحيث تتماشى مع التطورات السريعة والمتلاحقة التي تميز هذا الماتها العالم. 
وتعتبر العلوم من المجالات الدراسية التي نالت اهتمام الأوساط التربوية، فانصبت معظم الجهود والحركات الإصلاحية التي تهدف إلى إصلاح التعليم في التركيز بشكل أساسي على تطوير تعليم اللغة العبرية.

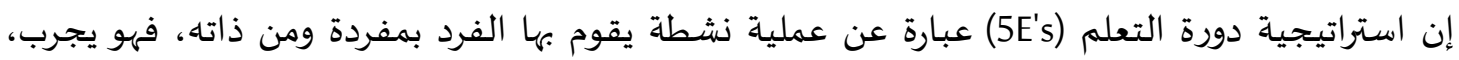

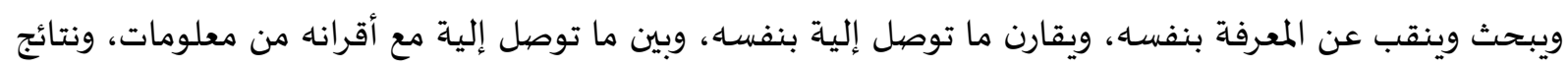
ذات أهمية (مكسيموس، 2003). لقد نادى التربويون وعلماء النفس بالاهتمام بعمليات التفكير وأساليبه، ودعوا إلى ضرورة العمل من أجل المكاء

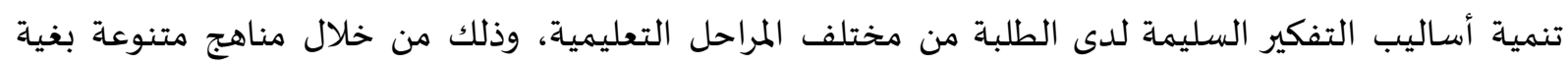

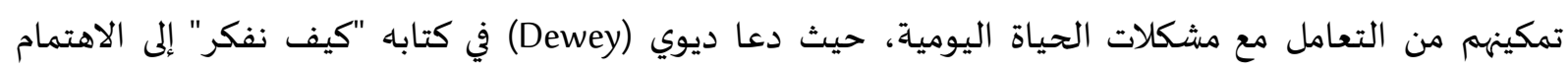

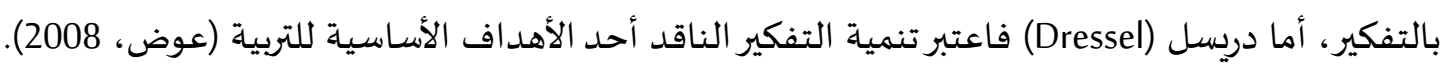

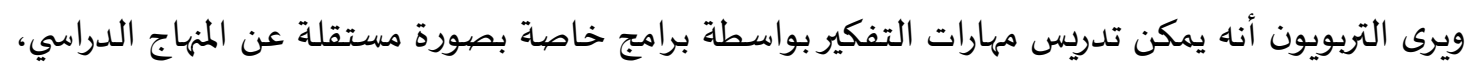

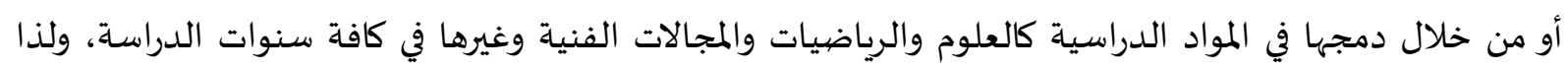

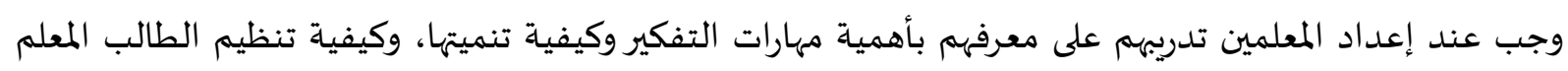
لأنشطة تساعد في تنمية مهارات التفكير لرفع مستوى طلبته العقلي والفكري (سعادة، 2003).

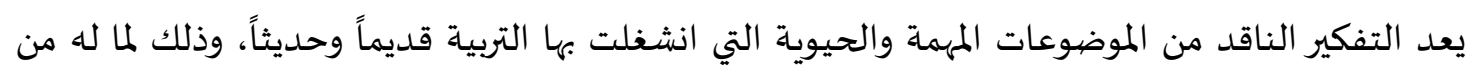

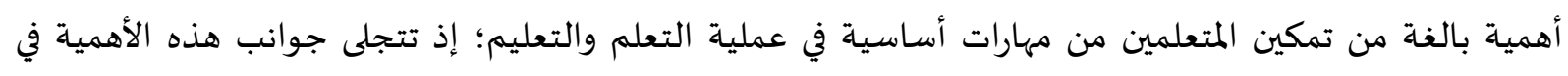

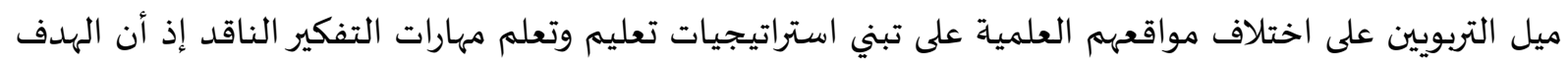

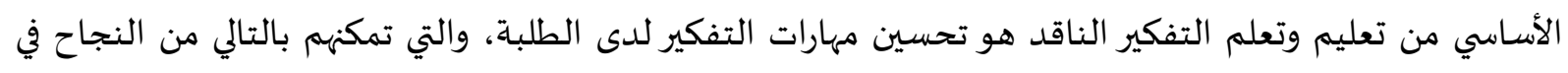

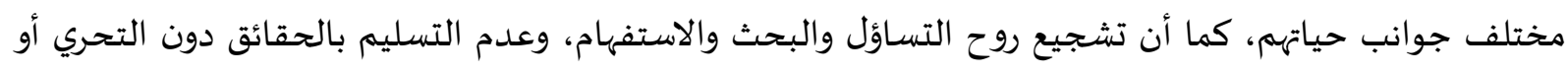

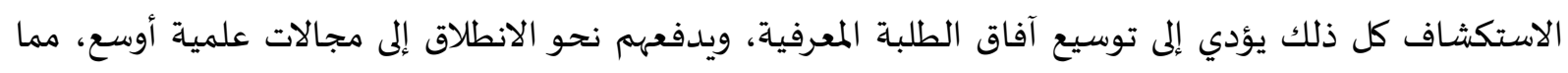

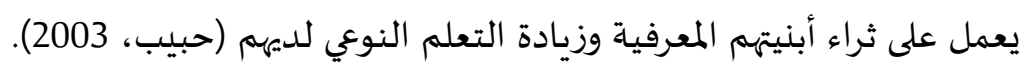

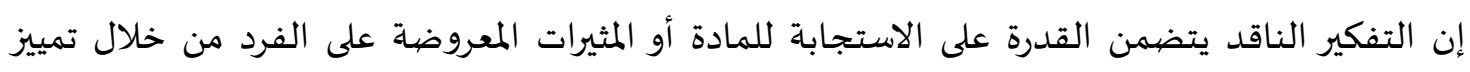

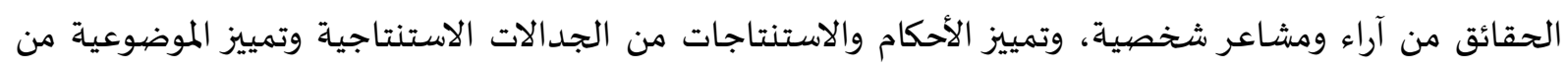
الأحكام الشخصيية. (نوفل وسعيفان، 2011).

مشكلة الدراسة: يعد تحسين التحصيل العلمي في مختلف المراحل الدراسية من خلال استخدام أساليب وطرق التدريس

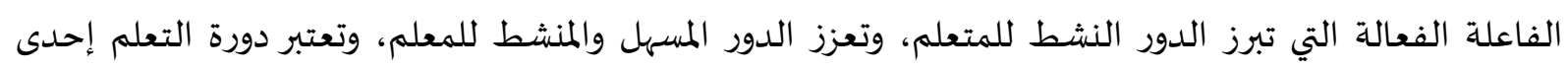

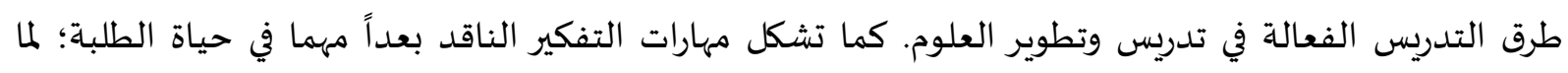

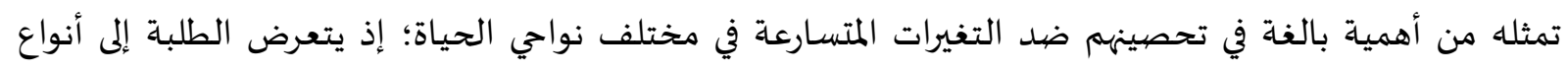

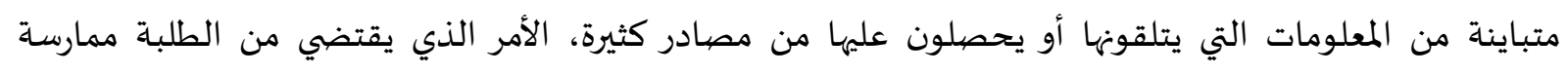
مجموعة من مهارات التفكير الناقد (عبد العزيز، 2007).

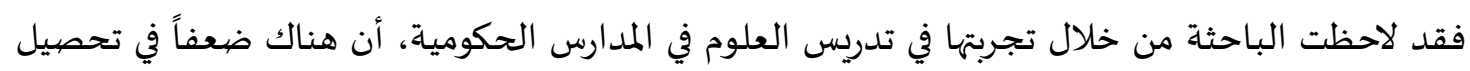

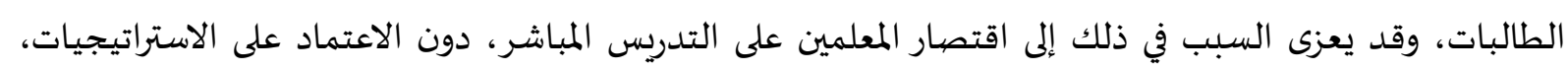

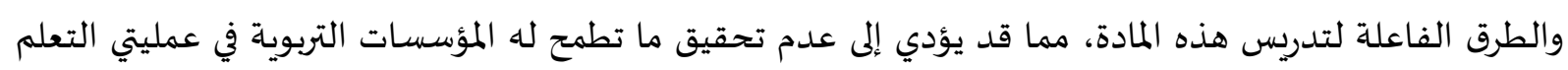
والتعليم. 
ومن هنا جاءت هذه الدراسة لمعرفة أثر استخدام استراتيجية دورة التعلم (5E's) في التحصيل وتنمية مهارات التفكير الناقد في العلوم لدى طالت هذه لدراست المعرفة ائر الصفيخ الثامن الأساسي في الأردن.

أسئلة الدراسـة:

بناء على ما سبق؛ يمكن تحديد مشكلة الدراسة في السؤالين التاليين:

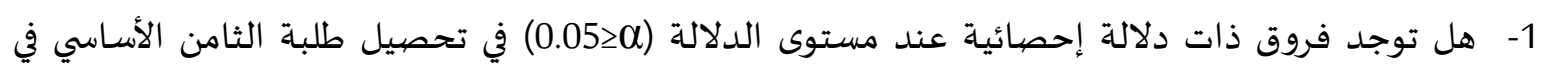
مادة العلوم لدى طالبات الصف الثامن الأساسي تعزى لطريقة التدريس (استراتيجية دورة التعلم، الطريقة

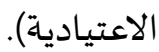
2- هل توجد فروق ذات دلالة إحصائية عند مستوى الدلالة (0.05>0) في اكتساب مهارات التفكير الناقد لدى الدي طالبات الثامن الأساسي في مادة العلوم تعزى لطريقة التدريس (استراتيجية دورة التعلم، الطريقة

$$
\text { الاعتيادية). }
$$

$$
\text { أهداف الدراسـة }
$$

تهدف هذه الدراسـة إلى التعرف على:

1- فاعلية استخدام استراتيجية دورة التعلم في تحصيل طالبات الصف التهات الثامن الأساسي في مادة العلوم.

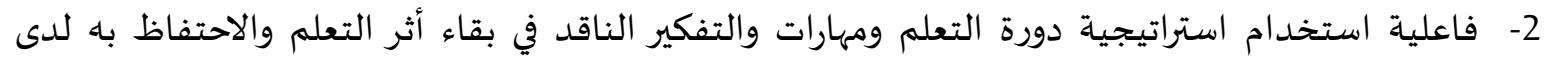

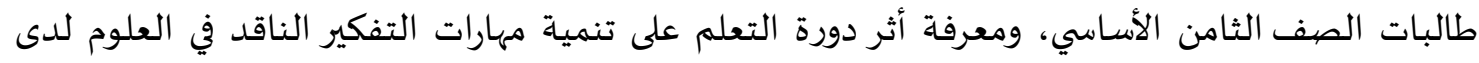
طالبات الصف الثامن الأساسي.

أهمية الدراسـة

تبرز أهمية هذه الدراسة من كونها تبين أثر توظيف استراتيجية دورة التعلم على تنمية المفاهيم ومهارات التفكير الناقد في العلوم لدى طلبة الصف الثامن الأساسي.

$$
\text { وكما تكمن أهمية هذه الدراسة في: }
$$

إظهار الفائدة التربوية من استخدام وتطبيق استراتيجية دورة التعلم في عملية التدريس، وتحسين مخرجات

$$
\text { التعليم. }
$$

وقد تُفيد نتائج هذه الدراسة معلمي العلوم والمشرفون التربويون لمادة اللغة العربية، بحيث توجههم نحو

تنويع طرق تدريس العلوم والأخذ باستراتيجية دورة التعلم.

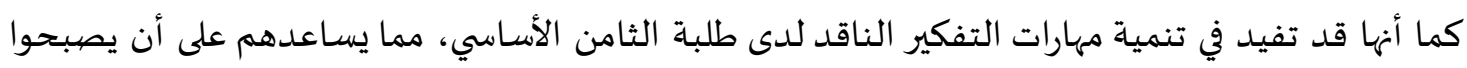

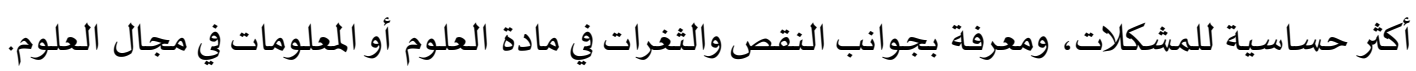

حدود الدراسة

اقتصرت الدراسة الحالية على الحدود التالية:

الحدود الموضيوعية: وحدة الكائنات الحية وبيئاتها من الفصل الأول من كتاب العلوم للصف التهاتية الثامن

الأساسي.

الحدود البشرية: عينة قصديه من طالبات الصف الثامن الأساسي. 
الحدود المكانية: مدارس مديرية التربية والتعليم في لواء الجامعة في العاصمة عمان، بواقع مدرسة واحدة هي مدرسة الجبيهة الثانوية للبنات. الحدود الزمانية: تم تطبيقها هذه الدراسة خلال الفصل الدراسي الثاني للعام (2020/2019).

مصطلحات الدراسة - دورة التعلم: نموذج معرفي للتعلم وبناء وتنظيم المحتوى الدراسي قائم على النظرية البنائية في التعليم والتعلم

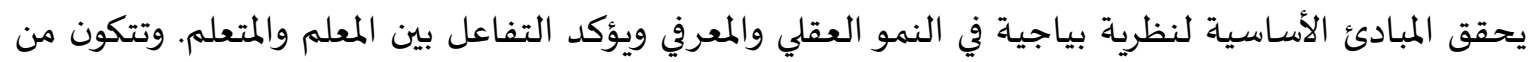
خمسة مراحل (الانشغال (Engage)؛ الاستكشاف (Explore)، التفسيه فئسير (Explain)، التوسع (Extend) ، التقويم

(Evaluate)

- التفكير الناقد: وهو استخدام المتعلم مهارات معرفة الافتراضات، والتفسير، وتقويم الأدلة، والاستنباط والاستنتاج في مواقف معينة، للوصول إلى استنتاجات وقرارات صحيحةة، مبررة ومدعومة بأدلة مقبولة. الصف الثامن الأساسي: هو الصف الثامن من المرحلة الأساسية في الأردن، ويكون عمر الطالب في هذه المرحلة

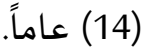

التحصيل: هو مقدار ما يكتسبه الطالب من معلومات وخبرات، ومعارف، ومهارات وكفايات، ومعطيات دراسياة،

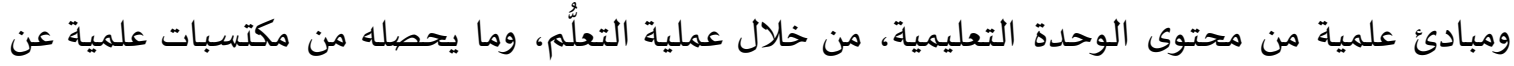

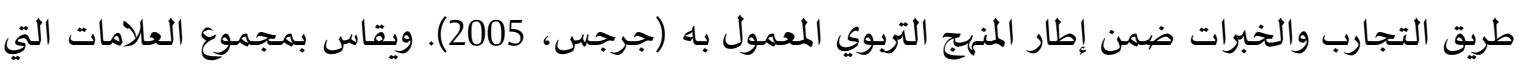

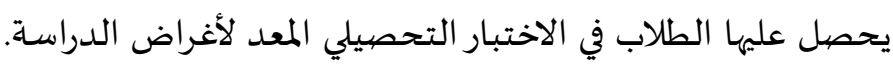

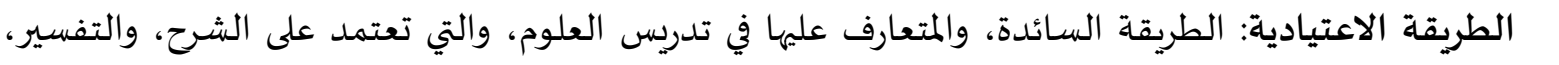
المناقشة، وطرح الأسئلة شفويا، وذلك اعتمادا على كتاب الطالب ودليل المعلم ويكون الدور الأكبر فيها للمعلم.

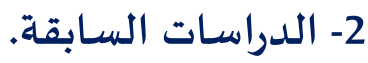
- أجرى أودوم وكيلي (Odom \& Kelly, 2001) دراسة هدفت إلى تحديد فاعلية استراتيجية تجمع دورة التعلم وخرائط المفاهيم على اكتساب مفاهيم الانتشار والخاصية الأسموزية لطالب المدارس الثانوية قسم الأحياء،

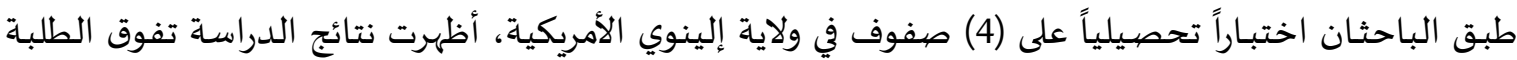

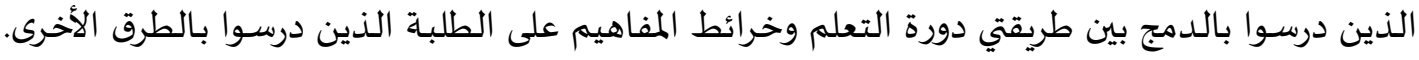
وهدفت دراسة بيلينقز (Billings, 2001) إلى تقصي فاعلية دورة التعلم في تعلم الفيزياء لدى طلاب المدارس الثانوية. وتكونت عينة الدراسة من (28) طالبًا من طلاب الصف الأول الثانوي. واستخدم الباحث الاختبارات القصيرة، والاختبار التحصيلي، ومقياس لقياس مستوى اهتمام الطلاب بالمادة العلمية وتمتعهم بدراسته.

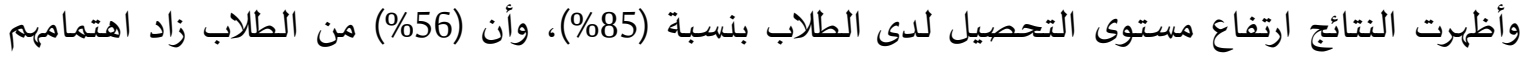

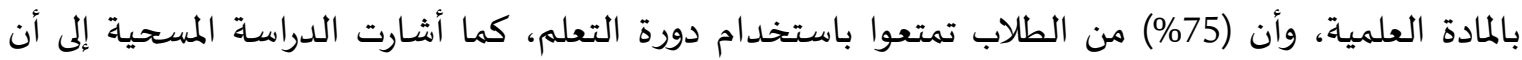

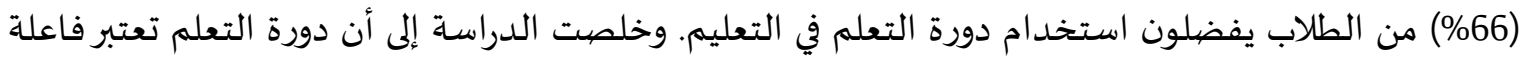
في عملية التعلم، وأنها تسهل عملية التعلم بطريقة ممتعة. - ـما قام الحربي (2002) بدراسة هدفت إلى قياس أثر استخدام العصف الذهني في تنمية التفكير الناقد والتحصيل الدراسي لدى عينة مكونة من (639) طالباً من طلبة الصف الأول الثانوي في مادة الأحياء بمدينة عرعر في السعودية، وتم تقسيمهم إلى مجموعتين: إحداهما تجريبية والأخرى ضابطلة، وأظهرت نتائج الدراسة 
وجود فروق دالة إحصائياً بين متوسط التحصيل البعدي للأهداف المعرفية من تصنيف بلوم لصالح المجموعة

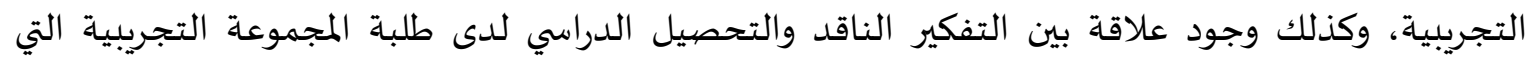

درست باستخدام العصف الذهني. كما قام الكندري (2005) بدراسة هدفت الكشف عن أثر استخدام برنامج إثرائي في مادة العلوم في تنمية مهارات

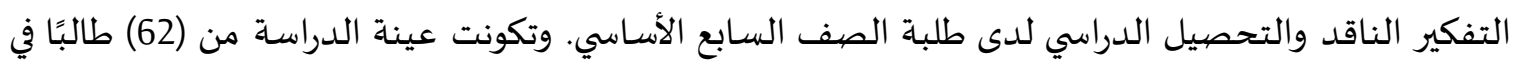

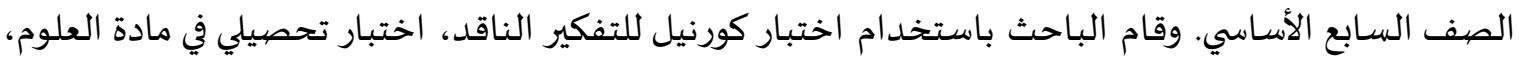

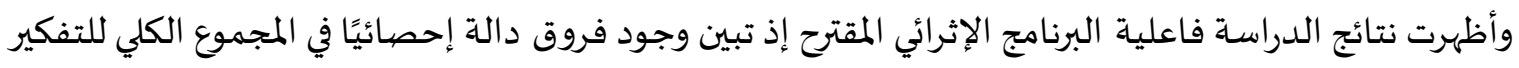

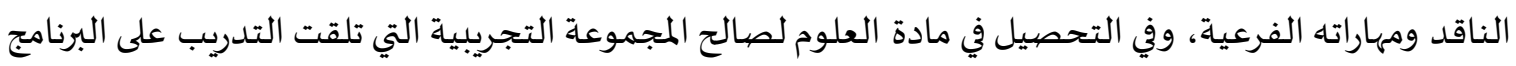
مقارنة بالمجموعة الضابطة التي لم تتلق أي تدريب. وأجرى كالروغلو (Cakiroglu 2006) دراسة هدفت لمعرفة أثر دورة التعلم(5E's) في تحصيل الطلاب لمادة العلوم، ولتحقيق هدف الدراسة استخدام الباحث اختبار لتحقق من أثر دورة التعلم في وحدة التهات التمثيل الضوفئي

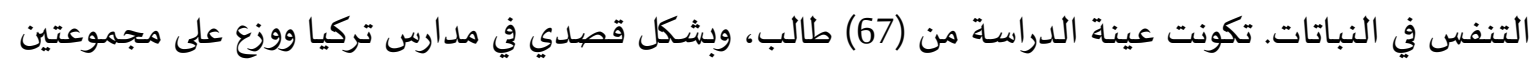

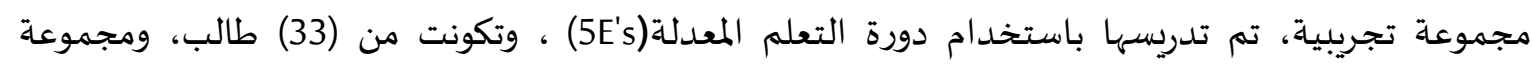

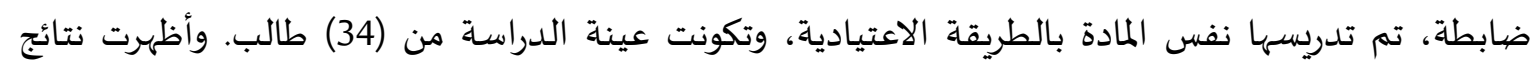

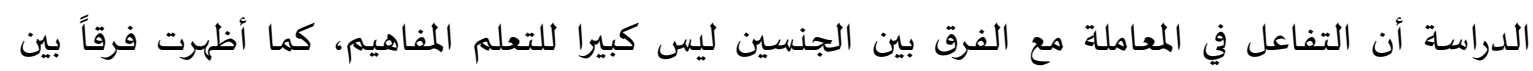

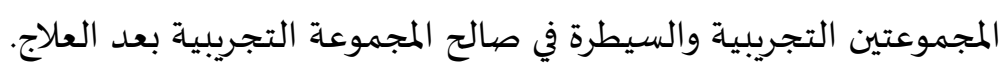

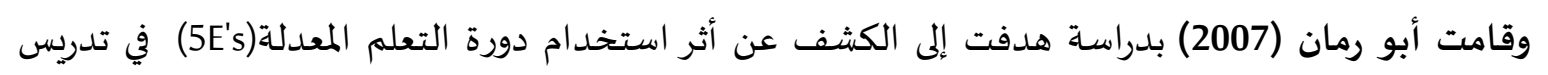
العلوم في اكتساب المفاهيم العلمية، وتنمية الاتجاهات العلمية لدى طلبة البان المرحلة الأساسية العليا في الأردن،

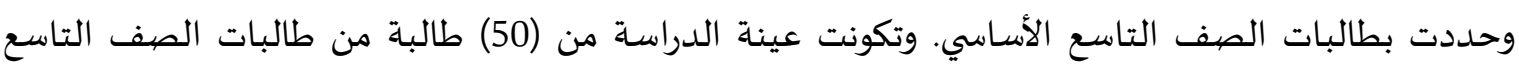

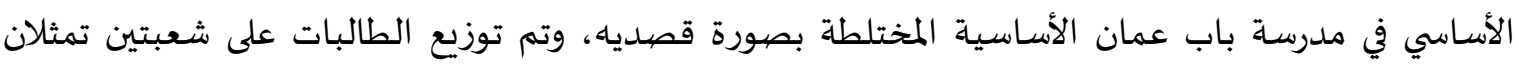

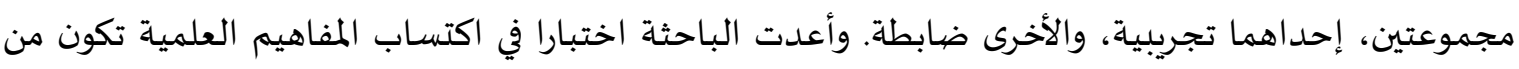

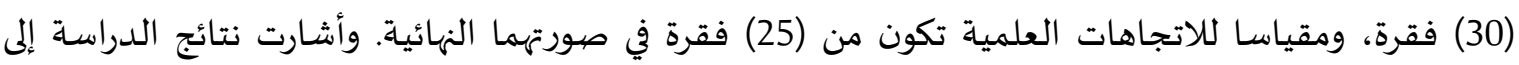

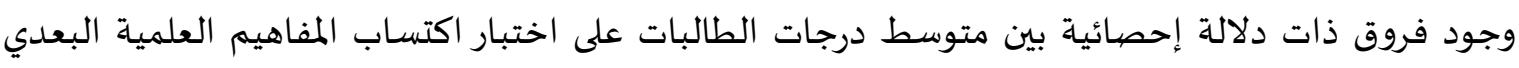

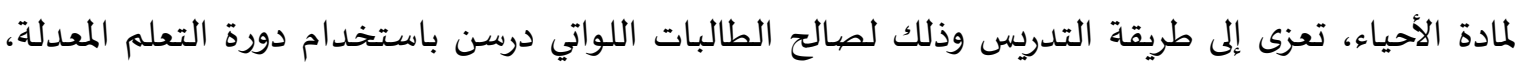

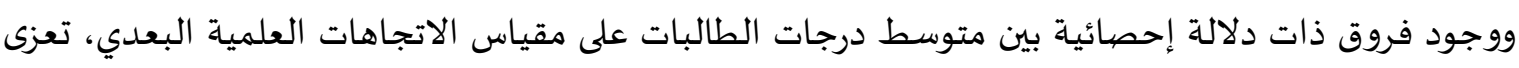

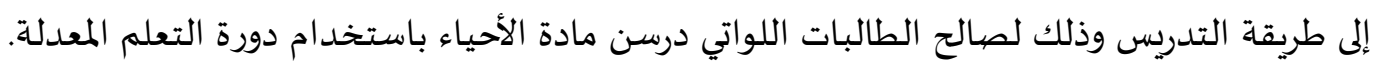
كما أجرى صالح (2008) دراسة هدفت إلى الكشف عن فعالية استخدام دورة التعلم فوق المعرفية في تنمية

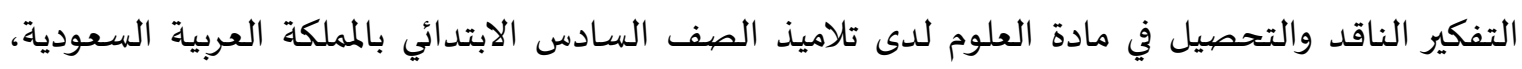

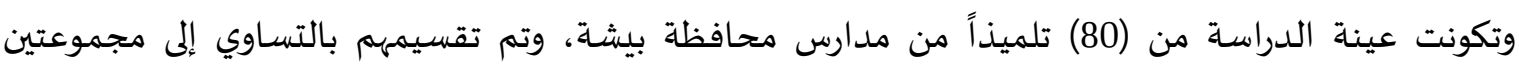

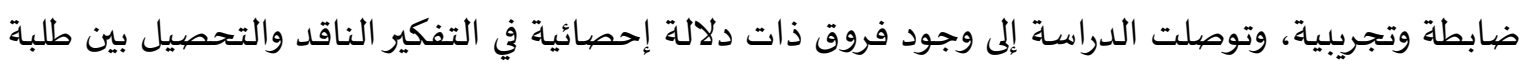

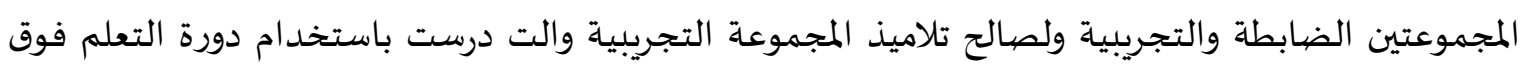
المعرفية. وهدفت دراسة اليتيم (2008) إلى الكشف عن أثر تكامل استراتيجيتين تستندان إلى فرضيات النظرية البنائية

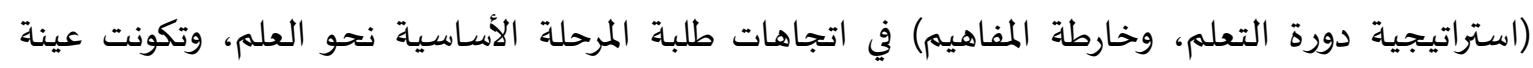

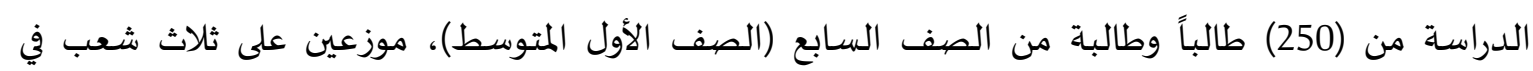


مدرسة للذكور وثلاث شعب في مدرسة للإناث، بحيث درست كل شعبة في كل مدرسة بإحدى الاستراتيجيات

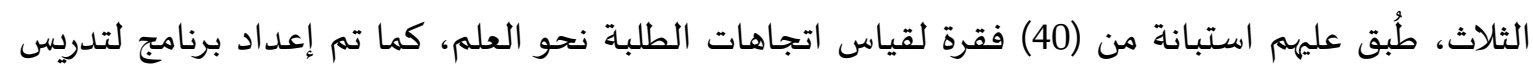

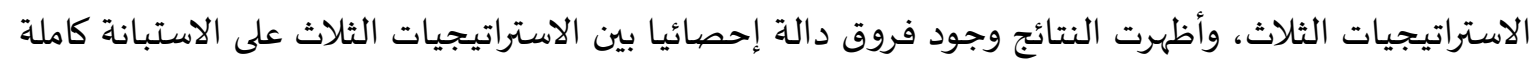

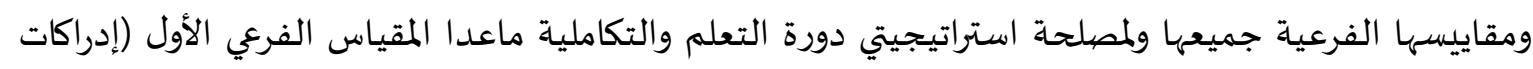

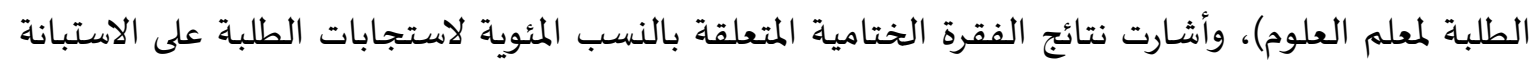

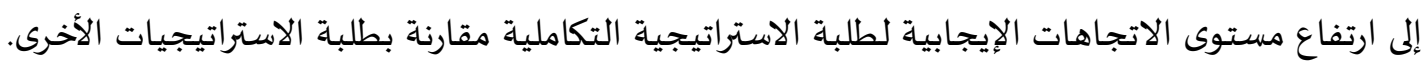
وأجرى الحوامدة (2005) دراسة هدفت إلى معرفة أثر استخدام استراتيجيتي العمل المخبري البنائي ودورة

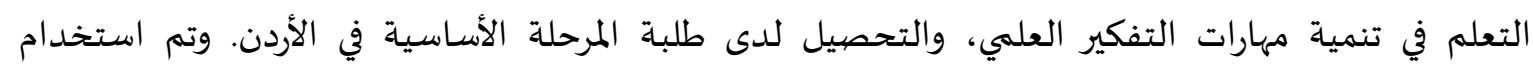
اختبارين: مقياس مهارات التفكير العلمي، واختبار التحصيل في وحدتي الحركة والتيل والقوة، والطاقة من من حولنا.

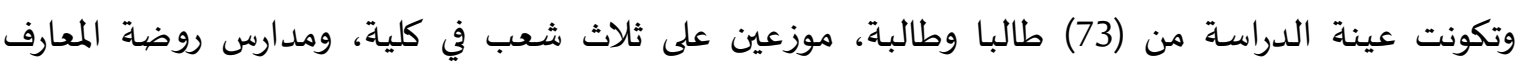

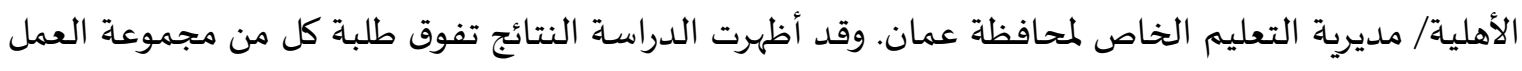

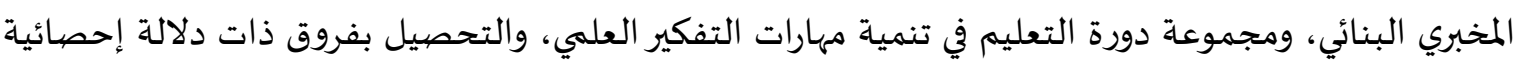

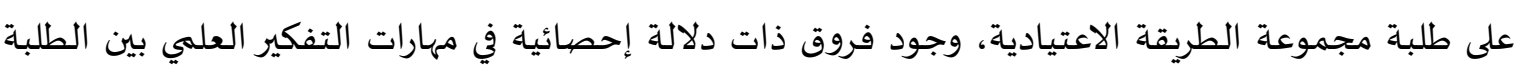

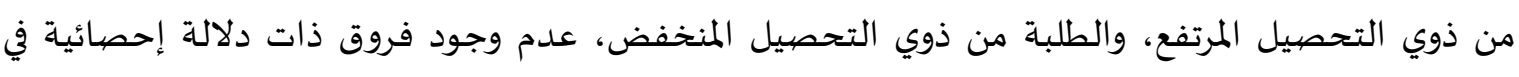

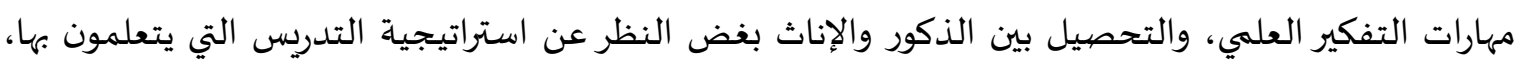

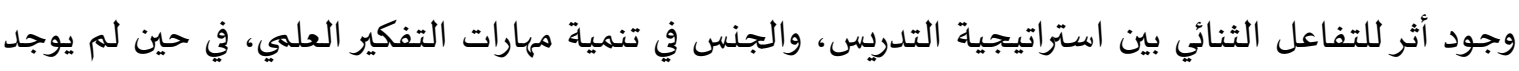

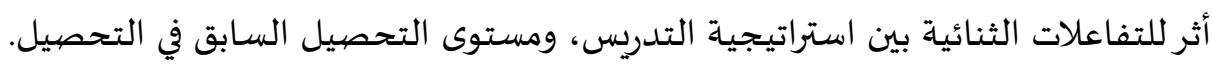

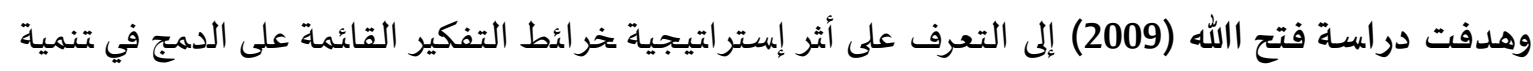

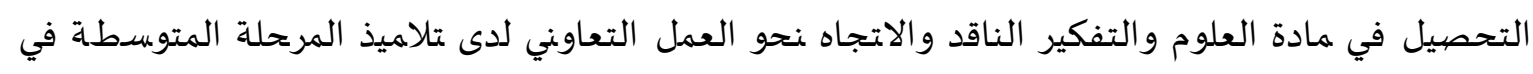

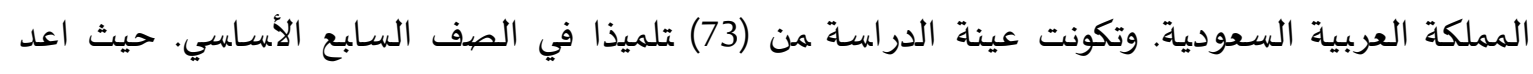

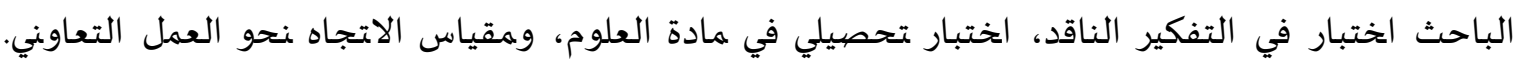

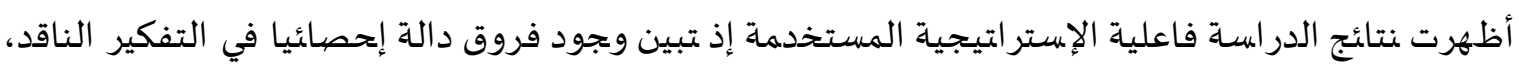

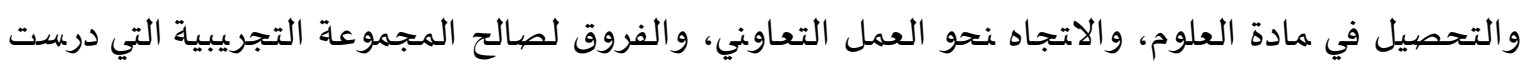

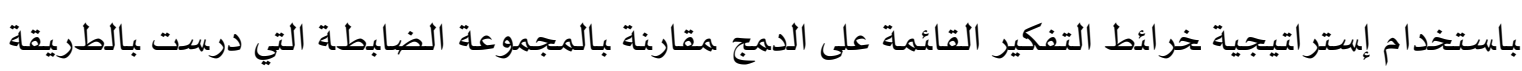
التقليدية. كما هدفت دراسة السفياني (2010) إلى الكشف عن أثر دورة التعلم في تدريس مادة الفيزياء على تنمية

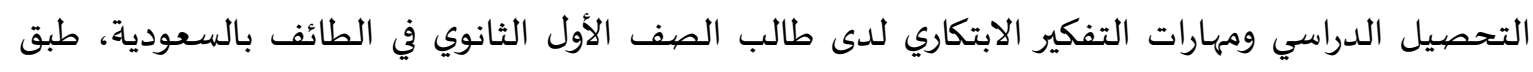

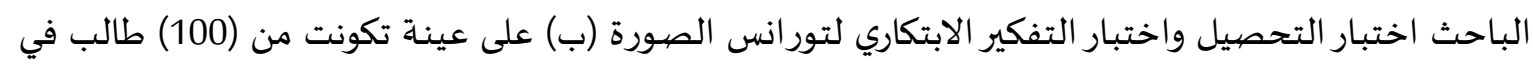

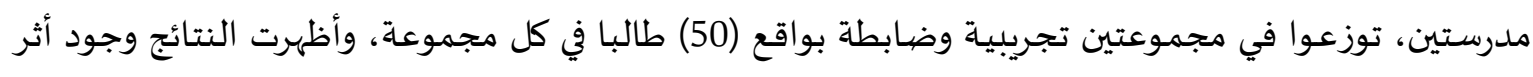

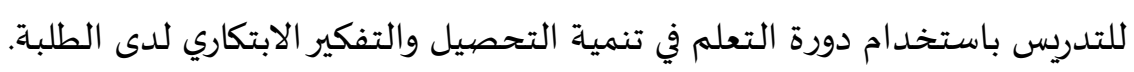
كما أجرت الوادعي (2017) دراسة هدفت إلى استقصاء أثر استخدام دورة التعلم الخماسي فيي تنمية مستوى مهارات

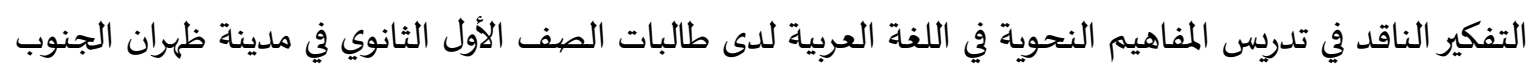
بالسعودية، واستخدمت الباحثة المنهج شبه التجريبي، وتكونت عينة الدراسة من (60) طالبة تم توزيعهن عشوائياً

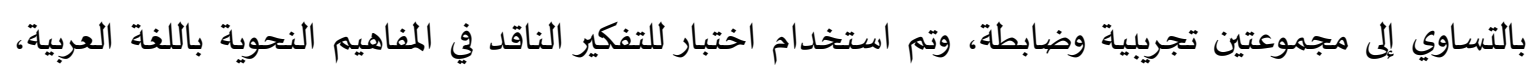


وتوصلت الدراسة إلى وجود أثر في استخدام دورة التعلم الخماسي في تنمية مستوى التفكير الناقد ومهاراته (التفسير

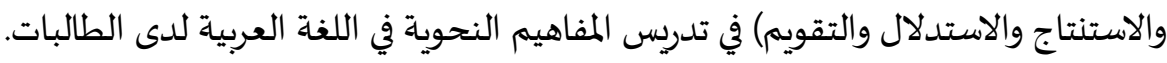

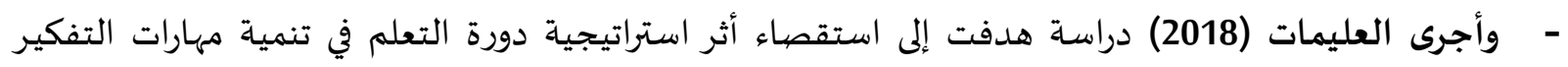

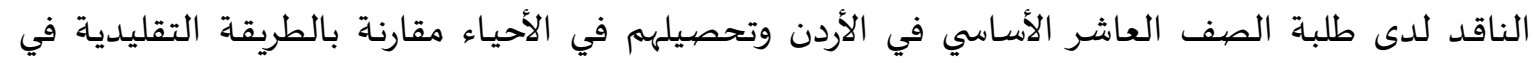

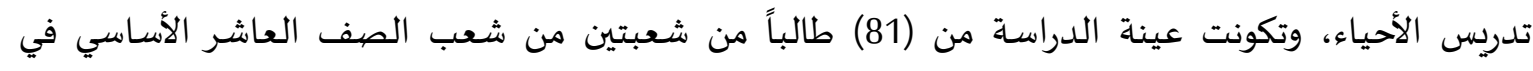

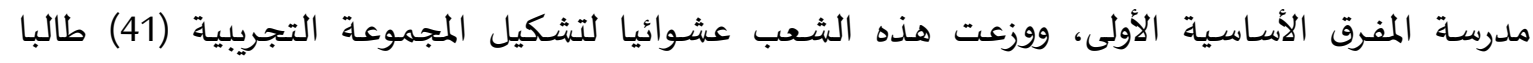

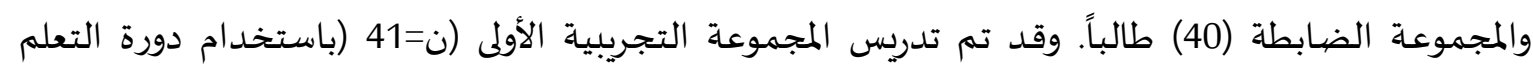

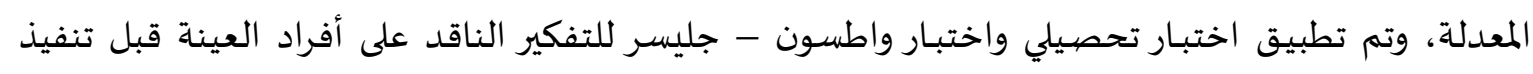

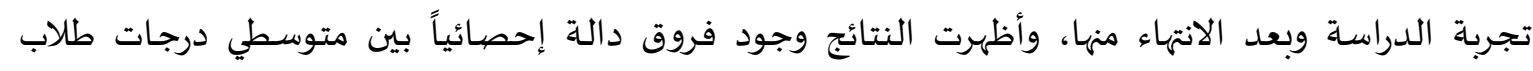

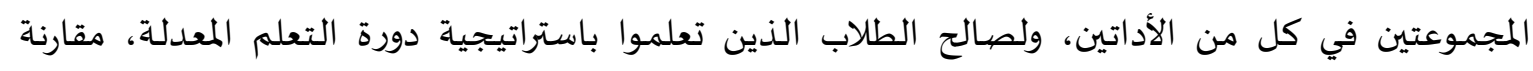
بنظرائهم الطلاب الذين تعلموا بالطريقة التقليدية. - وأجرى السويلمين (2019) دراسة هدفت الكشف عن فاعلية التدريس باستخدام استراتيجية دورة التعلم

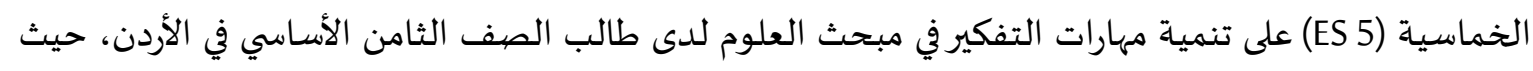

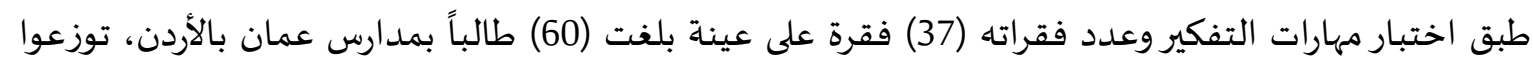

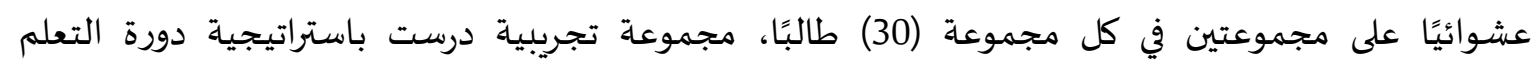

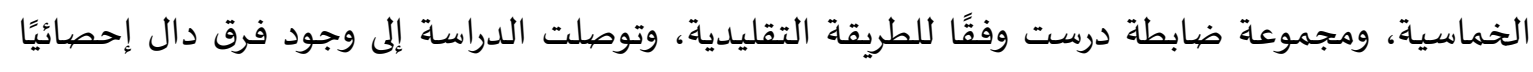

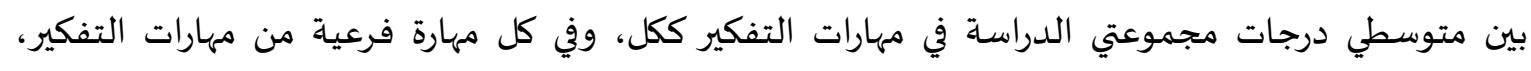

لصالح المجموعة التجريبية.

$$
\text { التعقيب على الدراسـات السـابقة }
$$

عند استعراض الدراسات نجد ما يلي السيات 1- - هنالك دراسات تناولت استخدام استراتيجية دورة التعلم في زيادة التحصيل لدى الطلاب، واكتسابهم

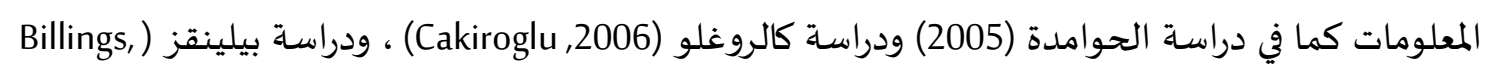

2- هنالك دراسات تناولت استخدام التفكير الناقد في زيادة التحصيل لدى الطلاب واكتسابهم المعلومات، كما

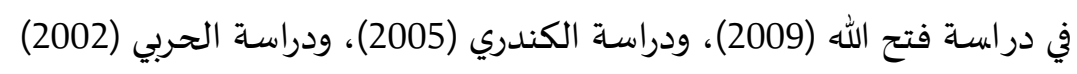

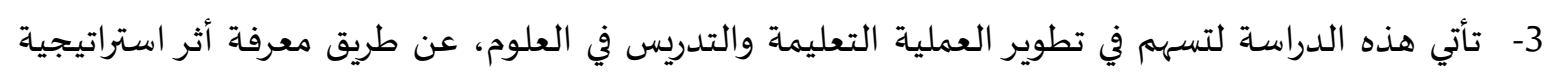

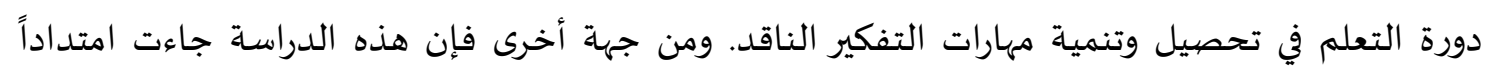
للعديد من الدراسات السابقة. 4- تمت الاستفادة من الدراسات السابقة في واختيار أدوات البحث، وضبط المتغيرات أثناء التجريب والمعالجة الماتة

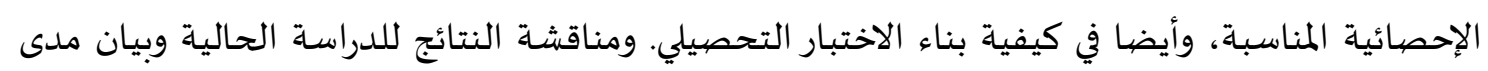
اتفاقها وتعارفها مع نتائج الدراسات السابقة.

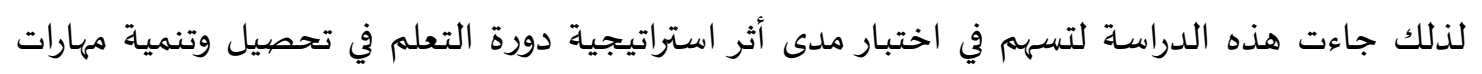
التفكير الناقد لدى طالبات الصف الثامن الاساسي في العلوم في الأردن. 


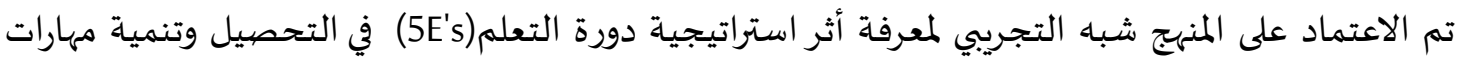

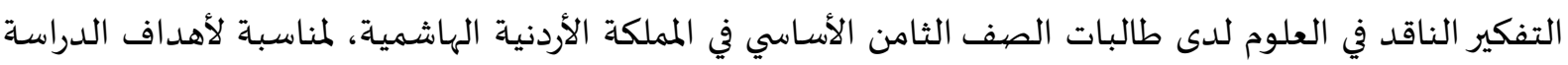
الحالية.

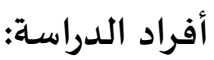
تكون مجتمع الدراسة من جميع طلبة الصف الثامن الأساسي للفصل الدراسي الثاني للعام الدراسي

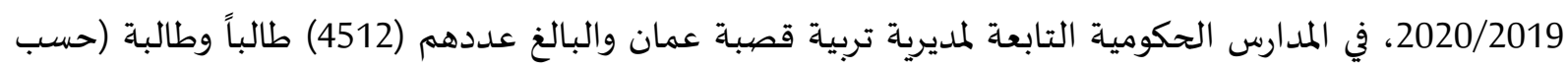

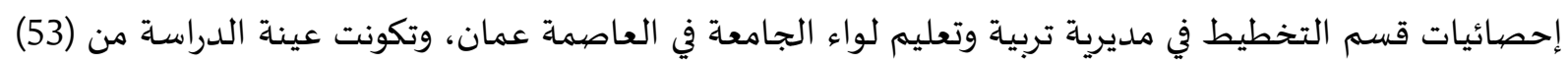

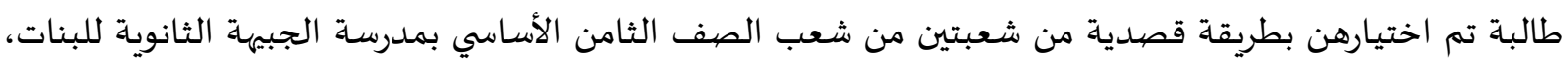

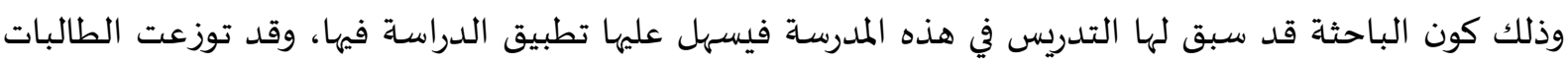

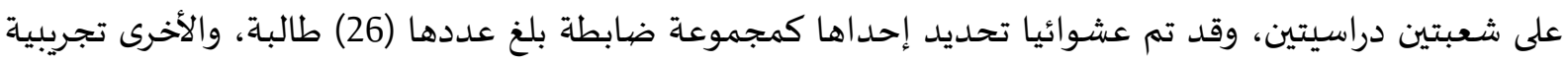
بلغت (27) طالبة.

$$
\text { أدوات الدراسة }
$$

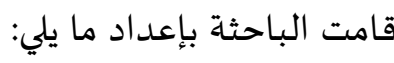

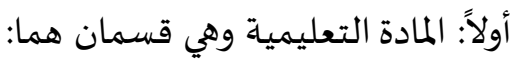

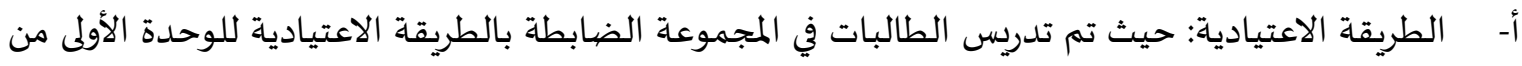

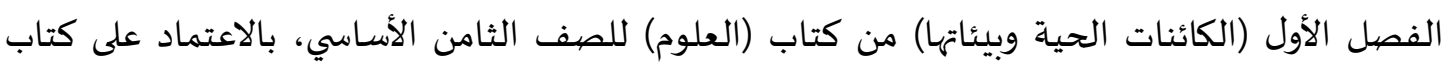

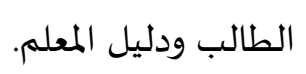

ب- استراتيجية دورة التعلم: قامت الباحثة بتحليل محتوى الوحدة الأولى من الفصل الأول (الكائنات الحية

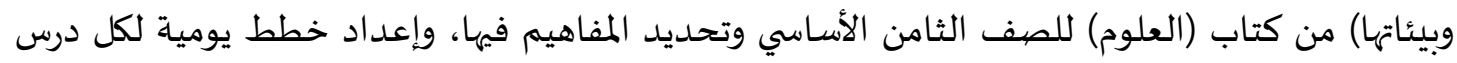

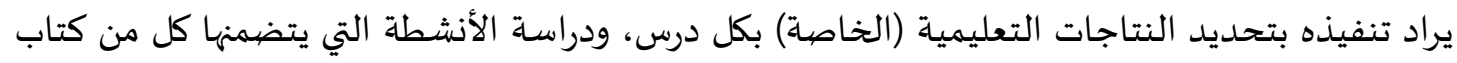

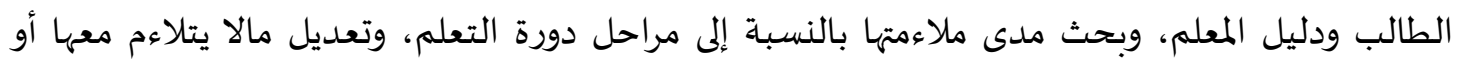

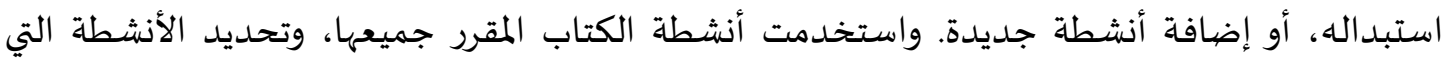

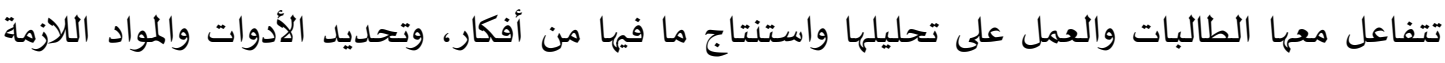

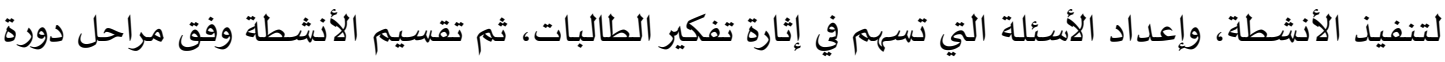

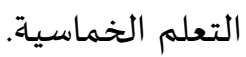
قامت الباحث بتوزيع المادة التعليمية المبنية بطريقة دورة التعلم على لجنة تحكيم مكونة من (13) محكماً

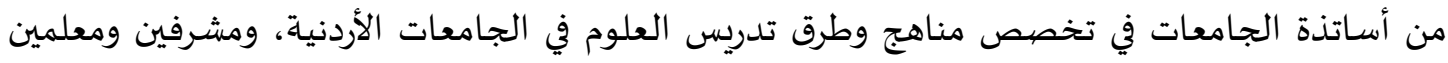

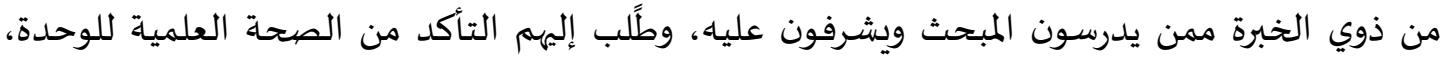

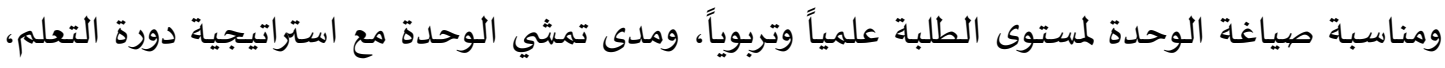

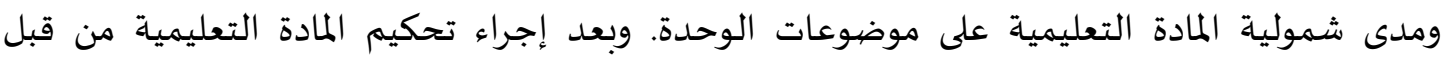
الأساتذة المحكمين تم إجراء التعديلات في ضوء المادة المراد تدريسها، وتم الاسترشاد بآرائهم وتعديلاتهم. 


\section{ثانياً: الاختبار التحصيلي}

تم إعداد اختبار تحصيلي من نوع الاختيار من متعدد، لتقويم مدى اكتساب الطالبات للمعلومات، بلغ عدد التدات

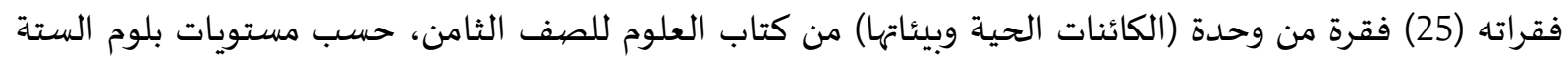

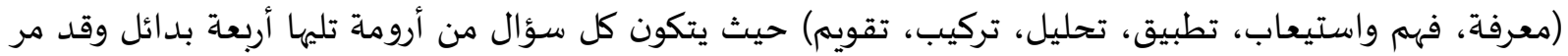

إعداد الاختبار بالمراحل التالية:

1- تحديد وحدة الدراسة التي سيتم تدريسهما باستخدام دورة التعائ: التعلم.

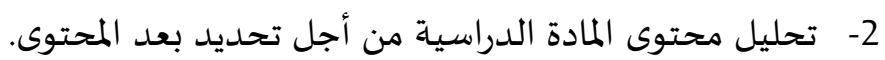

3- إعداد قائمة بالأهداف التعليمية اللازمة للمادة التعليمية تهدف إلى قياس تحصيل الطلبة حسب مستويات

بلوم الستة.

4- تم إعداد جدول مواصفات لاختبار تحصيل الطلبة في الوحدة الأولى من الفصل الأول (الكائنات الحية وبيئاتها)

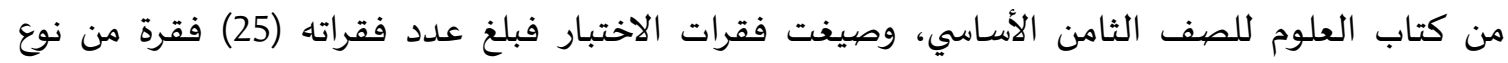

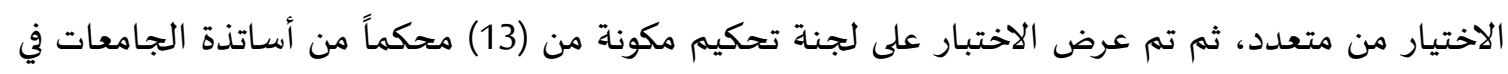

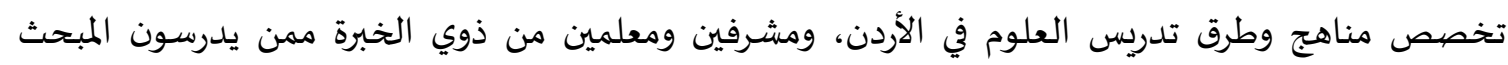

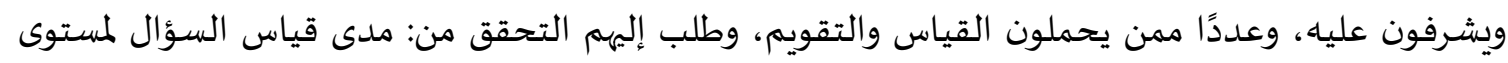

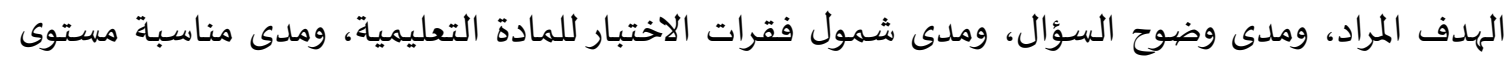

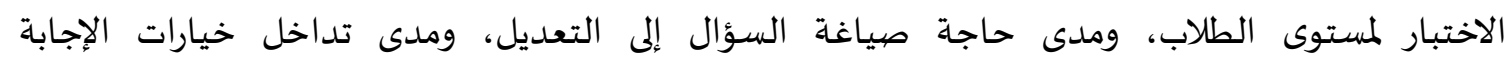
واستقلاليتها، وضيوح تعليمات الاختبار، والإجراءات السابقة تعد مؤشراً على صيدق الإق الاختبار.

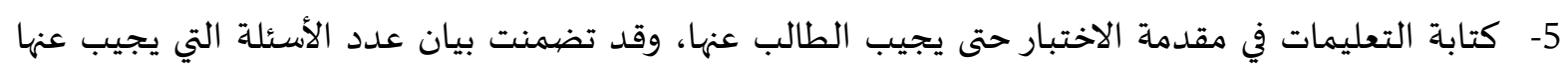

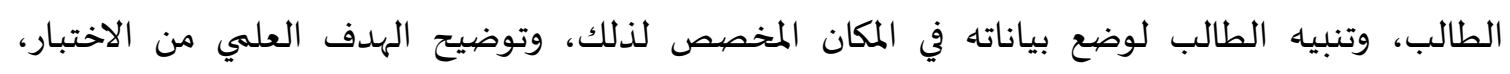

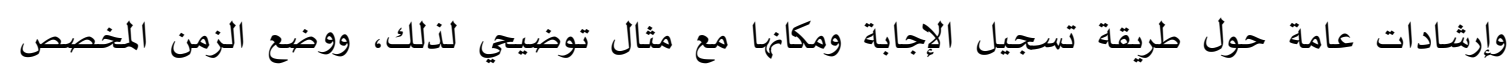

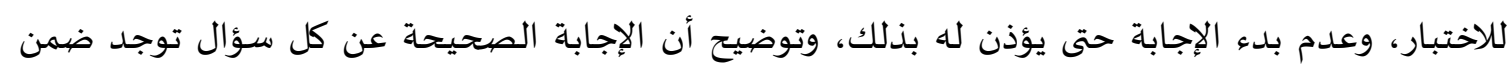

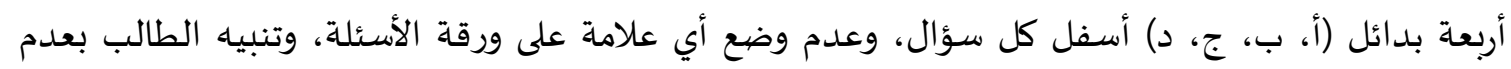

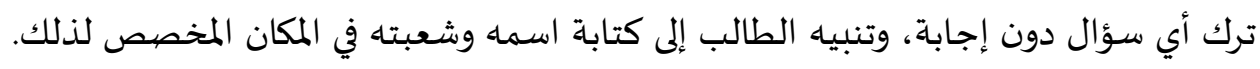
6- طريقة تصحيح الاختبار

تم رصدد درجة واحدة لكل سؤال من أسئلة الاختبار، حيث تضمن الاختبار بصورته الهائية (25) فقرة من

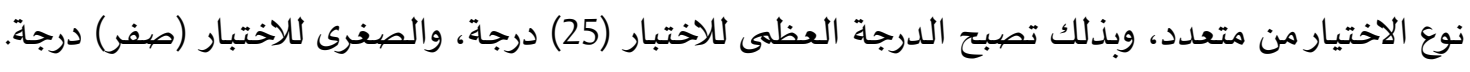

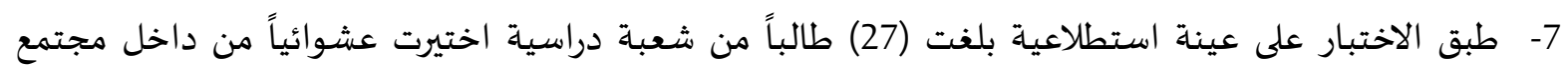
الدراسة ومن خارج عينتها، وذلك لتحديد زمن الاختبار التأكد من وضيوح المعاني وتعليمات الاختبار، وأيضاً للتحقق من الخصائص السيكومترية للاختبار وفقراته كما يلي:

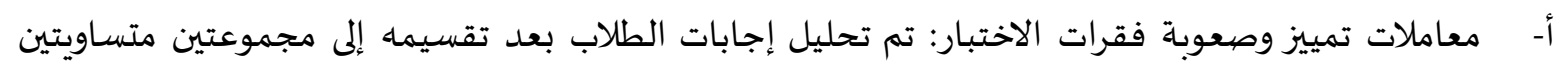

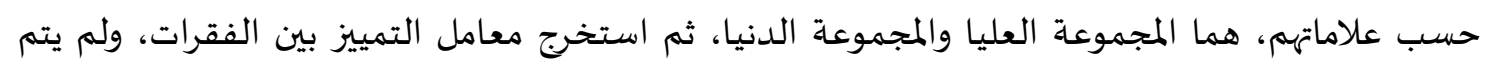

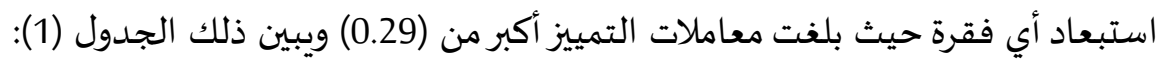




\begin{tabular}{|c|c|c|c|c|c|}
\hline معامل الصعوبة & معامل التمييز & الفقرة & معامل الصعوبة & معامل التمييز & الفقرة \\
\hline .32 & $.64^{* *}$ & 14 & .41 & $.77^{* *}$ & 1 \\
\hline .70 & $.45^{*}$ & 15 & .52 & .30 & 2 \\
\hline .67 & .33 & 16 & .37 & $.55^{* *}$ & 3 \\
\hline .63 & $.51^{* *}$ & 17 & .41 & $.63^{* *}$ & 4 \\
\hline .44 & $.49^{* *}$ & 18 & .63 & $.55^{* *}$ & 5 \\
\hline .26 & $.72^{* *}$ & 19 & .74 & $.39^{*}$ & 6 \\
\hline .37 & .35 & 20 & .59 & $.43^{*}$ & 7 \\
\hline .26 & .33 & 21 & .67 & .32 & 8 \\
\hline .52 & .25 & 22 & .30 & $.65^{* *}$ & 9 \\
\hline .41 & $.66^{* *}$ & 23 & .44 & $.40^{*}$ & 10 \\
\hline .48 & $.72^{* *}$ & 24 & .41 & $.56^{* *}$ & 11 \\
\hline \multirow[t]{2}{*}{.86} & $.39^{*}$ & 25 & .74 & $.41^{*}$ & 12 \\
\hline & & & .37 & $.54^{* *}$ & 13 \\
\hline
\end{tabular}

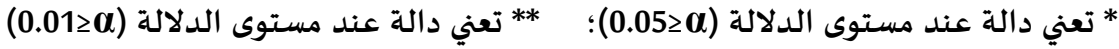

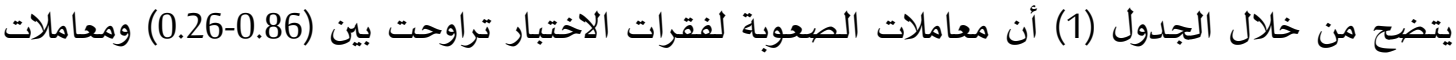

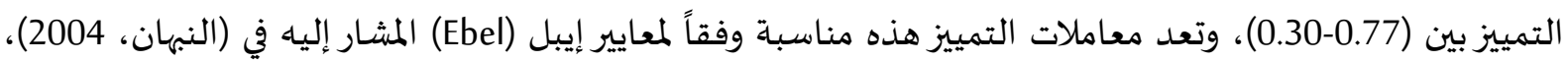
وقد تم اعتماد جميع الفقرات، مما يدل على مناسبة الفقرات لإجراء الاختبار. ب- بعات الاختبار

تم التحقق من ثبات الاختبار باستخدام ثبات الإعادة (Test Retest) حيث تم تطبيق الاختبار على العينة الاستطلاعية والبالغة (27) طالب، وتم ورصد درجات الطلاب، ثم أعيد تطبيق الاختبار على نفس أفراد العينة مرة

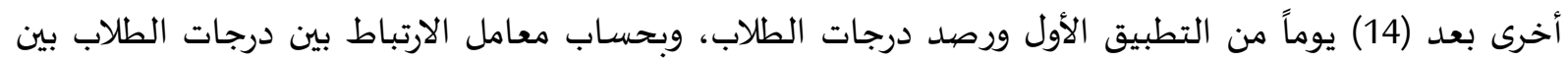

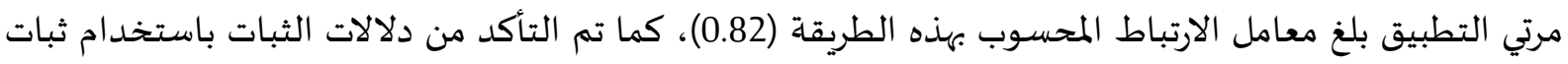

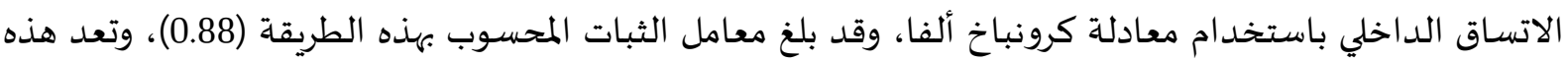

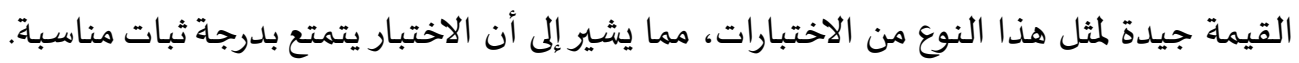

ثالثاً: اختبار التفكير الناقد

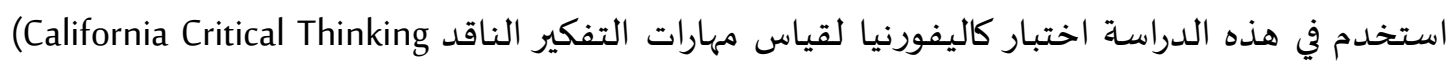

(6kills Test" CCTST"

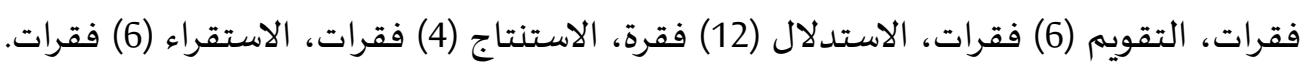

صدق اختبار التفكير الناقد تم التحقق من صدق الاختبار من خلال عرضيه على (15) محكماً من أساتذة الجامعة من المتخصصين في

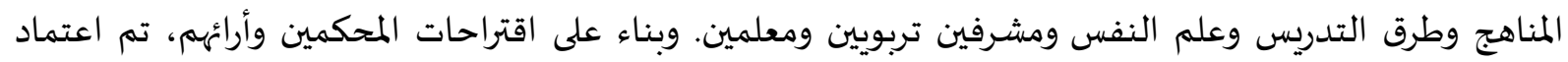
المقياس للتطبيق. 
ثبات اختبار التفكير الناقد

تم التحقق من ثبات اختبار تورانس عن طريق تطبيقه على طلاب العينة الاستطلاعية المذكورة سابقاً (ن=27)، وباستخدام معادلة كرونباخ ألفا للاتساق الداخلي بلغ منات معامل الثبات الثبات المحسوب (0.93) للاختبار ككل

وللمهارات كما في الجدول (2):

جدول (2) معاملات ثبات كرونباخ ألفا لاختبار كاليفورنيا لقياس مهارات التفكير الناقد

\begin{tabular}{|c|c|}
\hline معامل الثبات & المهارة \\
\hline 0.81 & التحليل \\
\hline 0.80 & التقوبم \\
\hline 0.82 & الاستدلال \\
\hline 0.80 & الاستنتاج \\
\hline 0.84 & الاستقراء \\
\hline 0.93 & الكلي \\
\hline
\end{tabular}

طريقة تصحيح اختبار كاليفورنيا للتفكير الناقد

سارت طريقة تصحيح التفكير الناقد على النحو الآتي:

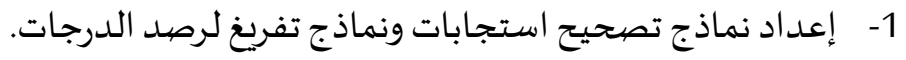

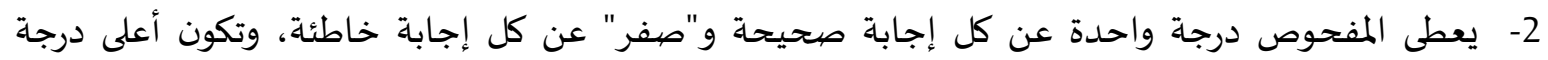

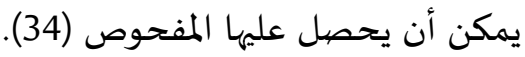

3- يحصل المفحوص على الدرجة الكلية لاختبار التفكير الناقد من مجموع الدرجات الكلية التي يحصل عليها في

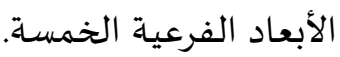

$$
\text { إجراءات الدراسة التباحثة الإجراءات التالية: }
$$

أولا: تم تصميم الوحدة الدراسية المختارة ليتم تدريسها بالطريقتين، وبطريقة تتوافق مع توزيع المنهاج

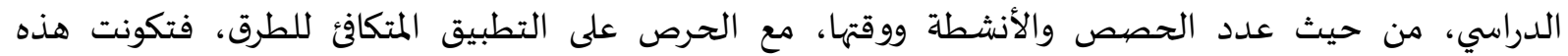

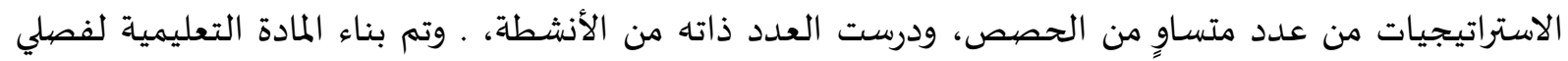

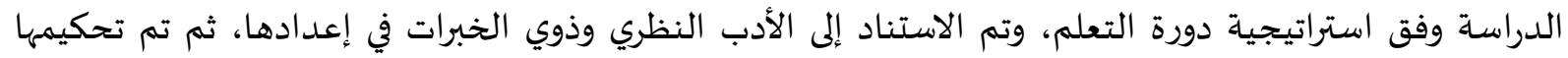

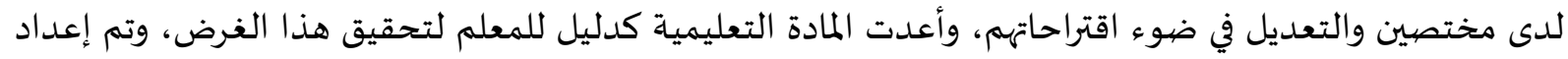
المادة التعليمية للوحدة وفق المراحل الآتية:

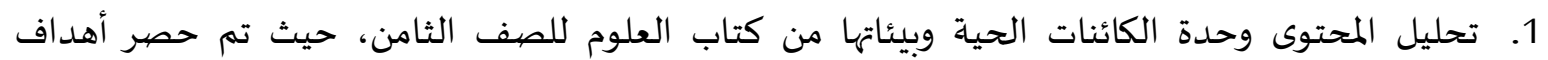

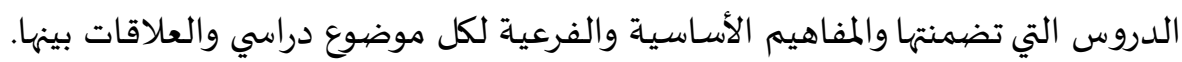

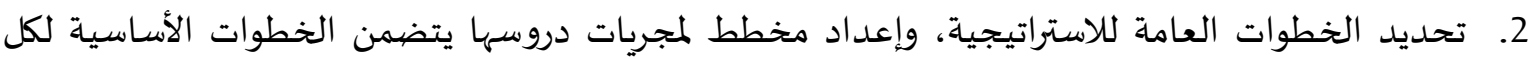

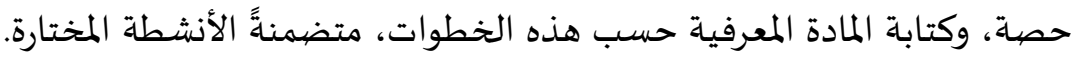
3. إعداد خربطة دورة التعلم وتضمينها بعد شرح الدرس. 
ثانيا: تصميم أداة الدراسة التي تم من خلالها قياس مدى تقدم الطالبات واكتسابهن للمعلومات علهيا، والمتمثلة بالاختبار التحصيلي. ثالثا: تقسيم شعب المدرسة إلى مجموعتين ضابطة (لا يتم تعريضها للبرنامج) وتجريبية (يتم تدريسهما بطريقة دورة التعلم) كما تم توضيحه سابقا في عينة الدراسة. رابعا: تم تدريب طالبات المجموعة التجريبية (دورة التعلم) على درس تجريبي سابق لتهبية للتطبيق وتم تدريبهن على خطوات هذه الاستراتيجيات. خامسا: تم تطبيق الاختبار التحصيلي واختبار التفكير الناقد على المجموعتين-كاختبار قبلي- للتأكد من

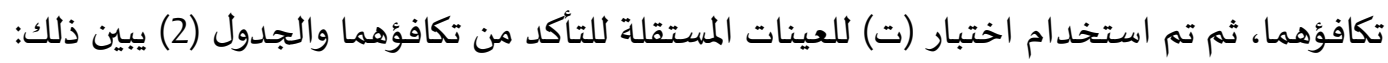

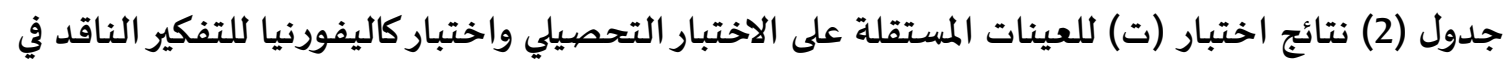
التطبيق القبلي

\begin{tabular}{|c|c|c|c|c|c|c|c|c|}
\hline مستوى الدلالة & قيمة & الحرية & والانحرافات & الأوساط الحسابية & علدد & المجموعة & \multicolumn{2}{|c|}{ الاختبار } \\
\hline \multirow{2}{*}{.703} & \multirow{2}{*}{$.384-$} & \multirow{14}{*}{51} & 5.32 & 9.61 & 26 & الضابطة & \multirow{2}{*}{\multicolumn{2}{|c|}{ التحصيلي }} \\
\hline & & & 4.78 & 10.15 & 27 & التجريبية & & \\
\hline \multirow{2}{*}{.973} & \multirow{2}{*}{.079} & & .99 & 1.58 & 26 & الضيابطة & \multirow{2}{*}{ التحليل } & \multirow{12}{*}{ التنفكبار } \\
\hline & & & .97 & 1.56 & 27 & التجريبية & & \\
\hline \multirow{2}{*}{.828} & \multirow{2}{*}{-.218} & & 1.47 & 1.65 & 26 & الضيابطة & \multirow{2}{*}{ التقويم } & \\
\hline & & & 1.43 & 1.74 & 27 & التجريبية & & \\
\hline \multirow{2}{*}{.592} & \multirow{2}{*}{.539} & & 1.72 & 3.92 & 26 & الضيابطة & \multirow{2}{*}{ الاستـلال } & \\
\hline & & & 1.82 & 4.18 & 27 & التجريبية & & \\
\hline \multirow{2}{*}{.950} & \multirow{2}{*}{.063} & & .99 & 1.46 & 26 & الضيابطة & \multirow{2}{*}{ الاستنتاج } & \\
\hline & & & .97 & 1.44 & 27 & التجريبية & & \\
\hline \multirow{2}{*}{.617} & \multirow{2}{*}{.503} & & 1.75 & 2.58 & 26 & الضيابطة & \multirow{2}{*}{ الاستقراء } & \\
\hline & & & 1.77 & 2.33 & 27 & التجريبية & & \\
\hline \multirow{2}{*}{.959} & \multirow{2}{*}{$.051-$} & & 4.62 & 11.19 & 26 & الضيابطة & \multirow{2}{*}{ الكلي } & \\
\hline & & & 4.85 & 11.26 & 27 & التجريبية & & \\
\hline
\end{tabular}

يتضح من الجدول (2) عدم وجود فروق ذات دلالة إحصائية عند مستوى الدلالة (a)

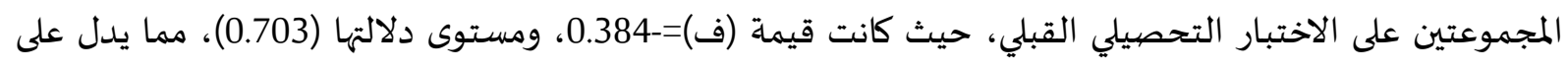

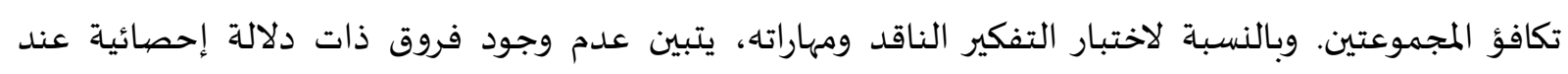
مستوى الدلالة (0.05>0) بين المجموعتين على القياس القبلي على الأبعاد وعلى الكلي.

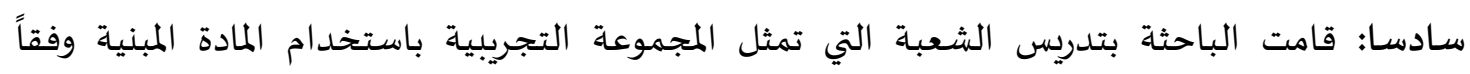

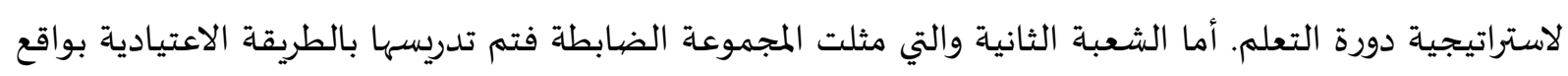
حصيتان دراسيتان للأسبوع الواحد لكل شعبة. سابعا: قامت الباحثة بعد شهر وهو الزمن اللازم لتدريس الوحدة بتطبيق أداة التقويم (الاختبار التحصيلي)

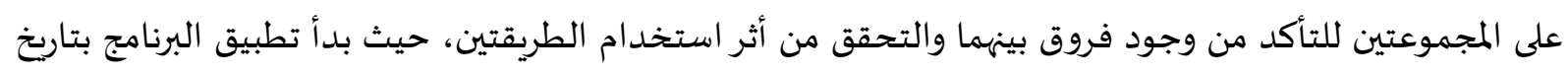


(2019/9/3)، وانتهى تطبيقه بتاريخ 2019/10/2، وطبق الاختبار التحصيلي بعد يومين كاختبار شهري أول للفصل الدراسي الأول.

$$
\text { متغيرات الدراسة: }
$$

1 - 1 - المتغيرات التابعة: وهي على مستويين: أ- التحصيل الدراسي يتم عن طريق إعداد اختبار تحصيلي للدروس التي يتم اختبارها من كتاب العلوم للصف الثامن الأسـاسي. ب- التفكير الناقد: ويتم قياسه عن طريق اختبار كاليفورنيا لقياس مهارات التفكير الناقد. 2- ألمتغيرات المستقلة: وهي استراتيجية التدريس ولهيا مستوينين: أ- الطر الطريقة الاعتيادية. ب- استخدام استراتيجية دورة التعلم.

المعالجات الإحصائية

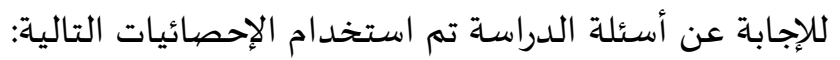
1- - المتوسطات الحسابية والانحرافات المعيارية. 2- اختبار (ت) للعينات المستقلة. 3- معامل ارتباط بيرسون لحساب ثبات الإعادة.

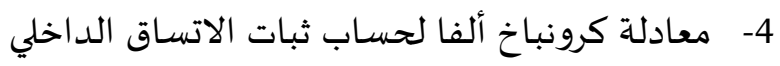

4. - نتائج الدراسـة ومناقشتها.

النتائج المتعلقة بالسؤال الأول: "هل توجد فروق ذات دلالة إحصائية (0>0.05) في تحصيل طالبات الثامن

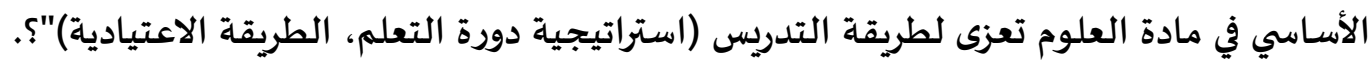

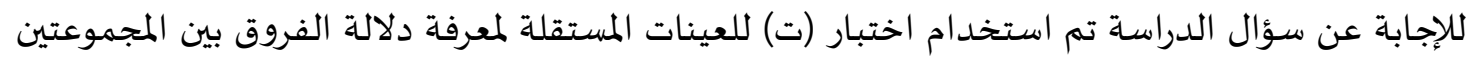
الضابطة والتجريبية على الاختبار التحصيلي، والجدول (3) يبين نتائج التحليل:

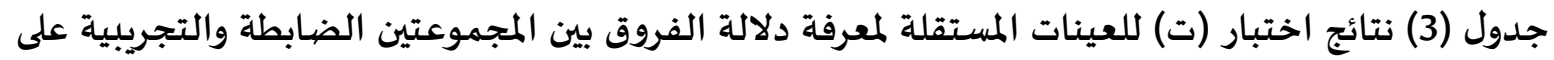
الاختبار التحصيلي

\begin{tabular}{|c|c|c|c|c|c|c|}
\hline مستوى الدلالة & قيمة (ت) & درجة الحرية & والانحرافات & الأوساط الحسابية & علاد & المجموعة \\
\hline \multirow{2}{*}{.012} & \multirow{2}{*}{ 2.62- } & \multirow{2}{*}{51} & 6.09 & 13.27 & 26 & الضابطة \\
\hline & & & 4.61 & 17.15 & 27 & التجريبية \\
\hline
\end{tabular}

يتبين من النتائج الواردة في الجدول (3) وجود فروق ذات دلالة إحصائيةً عند مستوى دلالة (م>0.005) متوسطي درجات تلاميذ المجموعة التجريبية "التي تدرس الوحدة باستخدام أسلوب دورة التعلم "، والمجموعة الماتها الضابطة التي تدرس نفس الوحدة بالطريقة العادية في التطبيق البعدي للاختبار التحصيلي، حيث بلغت فئت قيمة (ت)

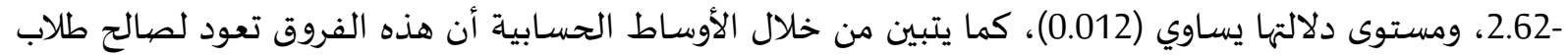

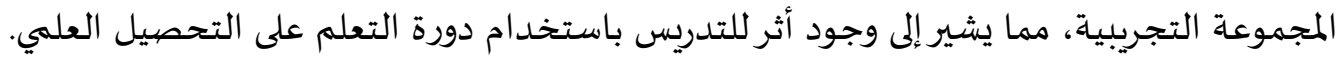


ويمكن أن يرجع السبب في تفوق استراتيجية دورة التعلم على الطريقة الاعتيادية في التحصيل إلى طبيعة

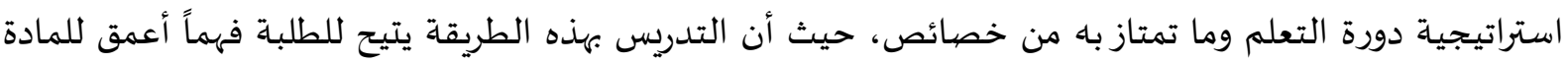

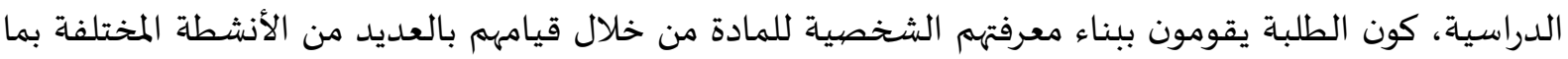

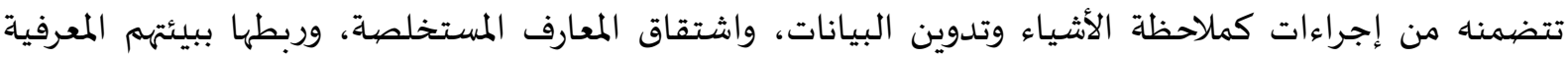

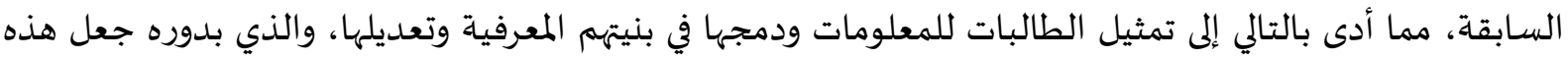

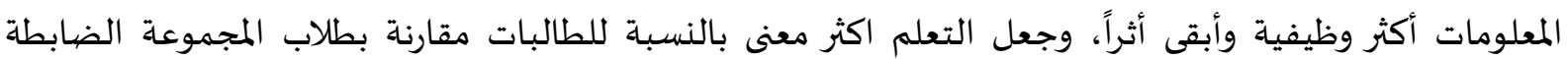
والذين التي استخدمت الطريقة الاعتيادية التي تعتمد على التلقين.

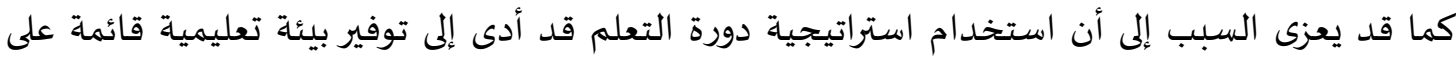

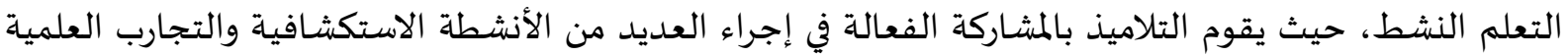
الحسية المختلفة، والإجابة عن التساؤلات الذاتية من خلال البحث عن المعلومات والوصول بنفسه إلى صياغة المفهوم وربط المفاهيم الحالية بما لدياء من خبرات سابقة في بنيته المعرفية، وتطبيق ما تعلماه في مواقف تعليمية جديدة، بحيث يتم ذلك بشكل مترابط ومتسلسل ومتتابع، وهذا كله قد ساعد على زيادة إقبال الطالبات نحو تعلم موضيوعات فصلي الكتاب، وتنفيذ الأنشطة بحماس وفاعلية، كما أدى ذلك إلى اكتساب الطالبات الخبرات وهدات المعرفية،

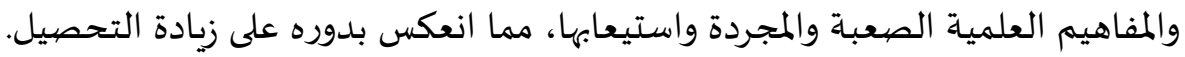

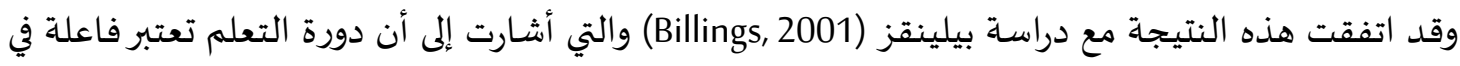

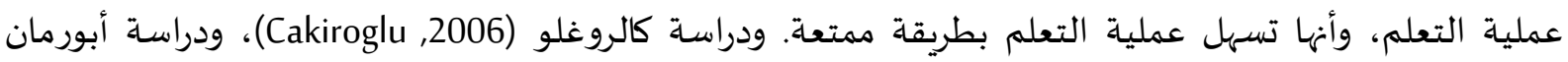
(2007) ودراسة صالح (2008).

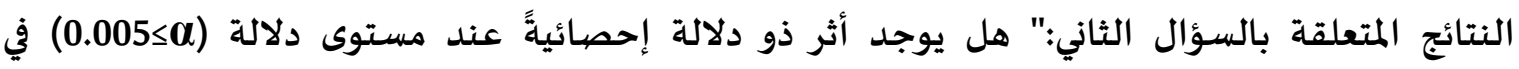

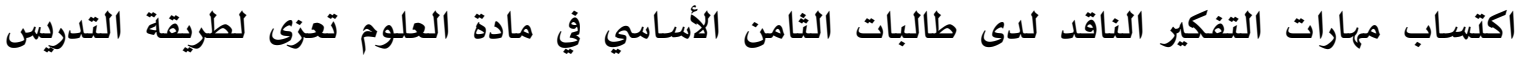

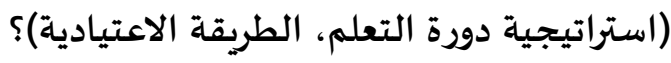

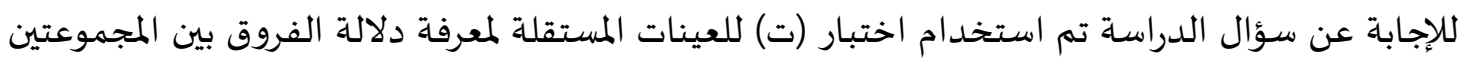

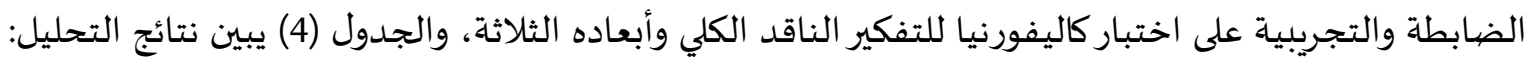

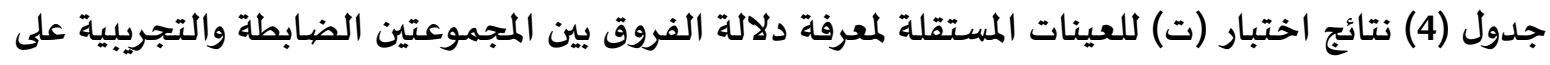
التفكير الناقد ومهاراته

\begin{tabular}{|c|c|c|c|c|c|c|c|}
\hline مستوى الدلالة & قيمة (ت) & الحرية & والانحرافات & الحسابية الحساط & علاب & المجموعة & البعد \\
\hline \multirow{2}{*}{.251} & \multirow{2}{*}{$1.16-$} & \multirow{8}{*}{51} & 1.35 & 2.81 & 26 & الضيابطة & \multirow{2}{*}{ التحليل } \\
\hline & & & 2.00 & 3.37 & 27 & التجريبية & \\
\hline \multirow{2}{*}{.041} & \multirow{2}{*}{$2.10-$} & & 1.59 & 2.59 & 26 & الضابطة & \multirow{2}{*}{ التقويم } \\
\hline & & & 1.52 & 3.59 & 27 & التجريبية & \\
\hline \multirow{2}{*}{.015} & \multirow{2}{*}{$2.52-$} & & 1.78 & 5.31 & 26 & الضابطة & \multirow{2}{*}{ الاستدلال } \\
\hline & & & 2.86 & 6.96 & 27 & التجريبية & \\
\hline \multirow{2}{*}{.005} & \multirow{2}{*}{ 2.93- } & & .97 & 2.08 & 26 & الضيابطة & \multirow{2}{*}{ الاستنتاج } \\
\hline & & & .95 & 2.85 & 27 & التجريبية & \\
\hline
\end{tabular}




\begin{tabular}{|c|c|c|c|c|c|c|c|}
\hline مستوى الدلالة & قيمة (ت) & الحرية & والاتحرافات & الحوساباطية & علدد & المجموعة & البعد \\
\hline \multirow{2}{*}{000} & \multirow{2}{*}{ 3.77- } & & 1.05 & 2.65 & 26 & الضيابطة & \multirow{2}{*}{ الاستقراء } \\
\hline & & & 1.17 & 3.81 & 27 & التجريبية & \\
\hline \multirow{2}{*}{.003} & \multirow{2}{*}{ 3.14- } & & 5.15 & 15.73 & 26 & الضيابطة & \multirow{2}{*}{ الكلي } \\
\hline & & & 6.46 & 20.59 & 27 & التجريبية & \\
\hline
\end{tabular}

يتبين من النتائج الواردة في الجدول (4) عدم ودود فروق في مهارة (التحليل) من مهارات التفكير الناقد بين

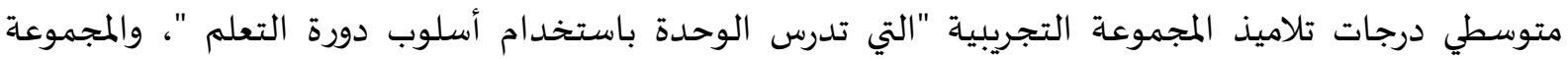

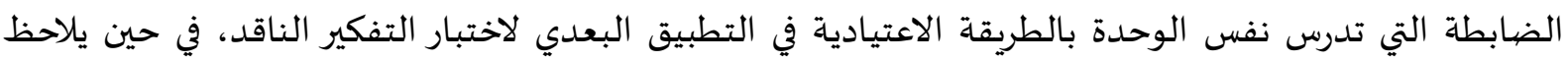

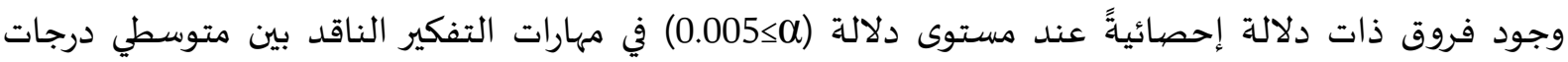

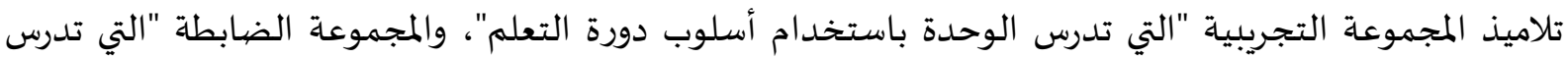

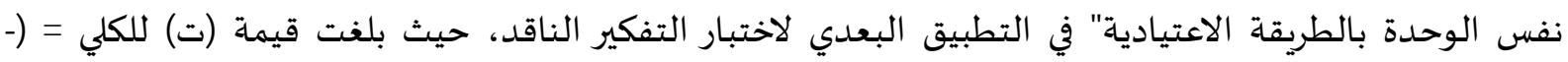

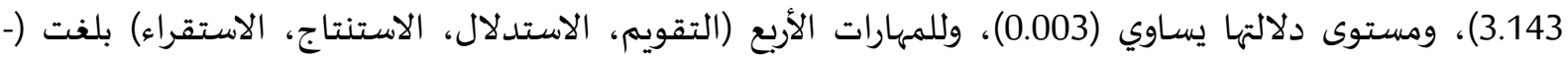

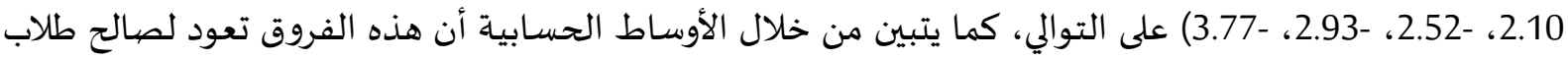

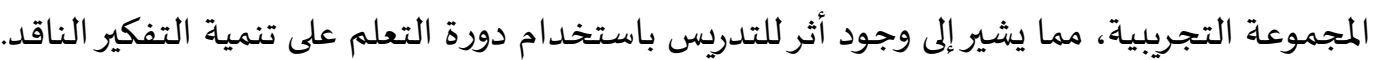

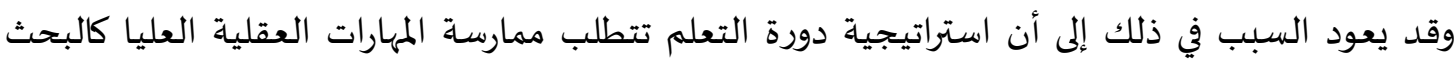
والتقصي والملاحظة الدقيقة والتفسير والاستنتاج، وتقويم الحجج والدقة في فحص الوقائع، فإذا ما تمعنا في هذه الدها

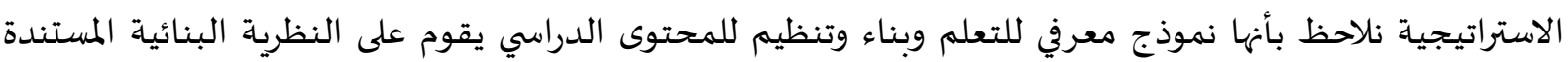

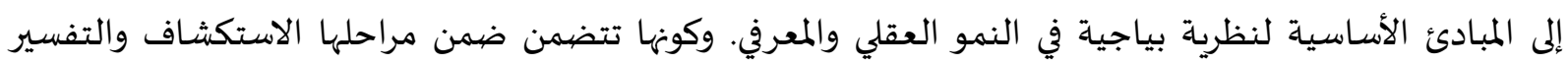

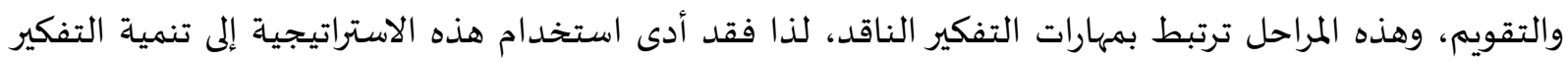

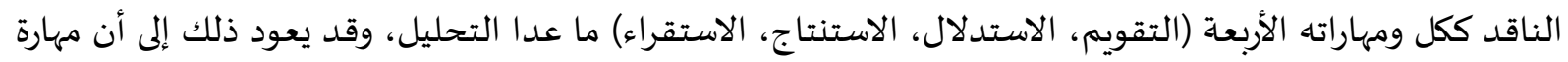

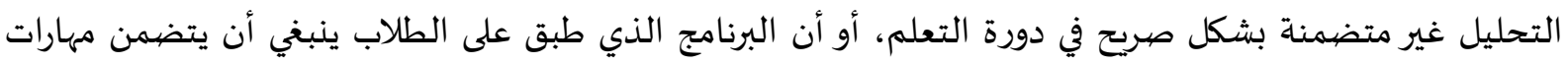
إضافية لكي يتم معرفة أثر ذلك على مهارة التحليل. وقد اتفقت هذه النتيجة مع دراسة صالح (2008) والتي أشارت إلى فعالية استراتيجية دورة التعلم في تنمية

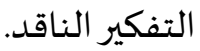

\section{التوصيات والمقترحات.}

في ضوء النتائج التي تم التوصل إليها توصي الباحثة وتقترح بما يلي:

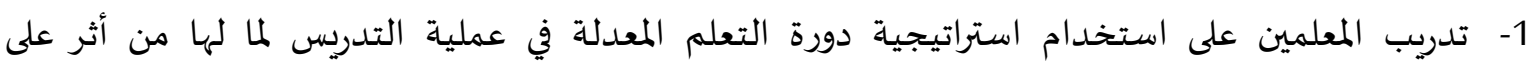
التحصيل وتنمية التفكير الناقد لدى الطلبة. 2- عقد الدورات والورش التعليمية للمشرفين والمعلمين لتوجيههم إلى أهمية استخدام دورة التعلم في عملية

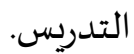
3- ضرورة أن يقوم واضعو المناهج بتضمين كتب العلوم بلدروس باستخدام دورة التعلم.

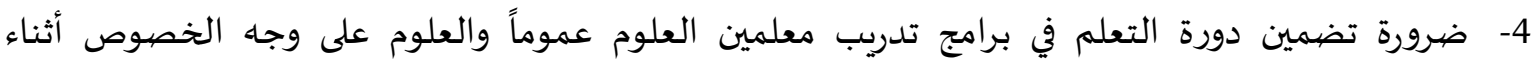

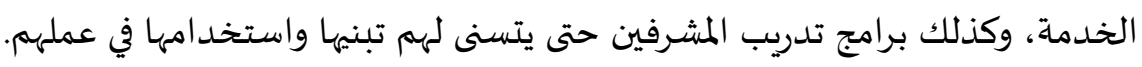


5- إجراء دراسات مماثلة على مجتمعات ومراحل دراسية أخرى، كتناول مجتمع الطالبات، والمرحلة المتوسطة.

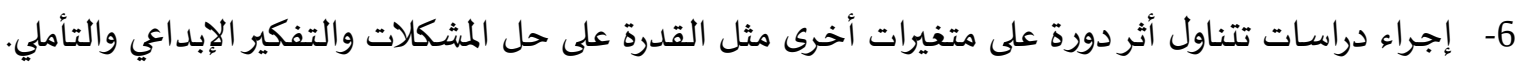

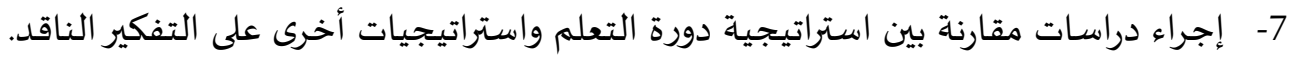

قائمة المراجع.

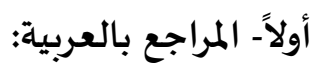

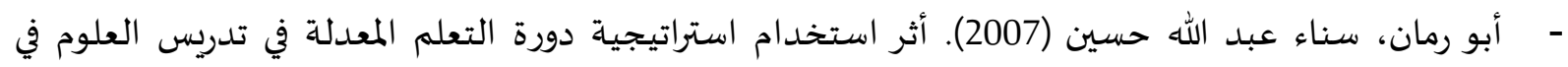

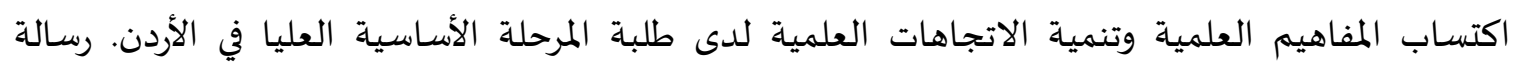
ماجستير غير منشورة، جامعة عمان العربية للدراسات العليا، الأردن. حبيب، مجدي (2003). اتجاهات حديثة في تعليم التفكير: استراتيجيات مستقبلية للألفية الجديدة، القاهرة: دار الفكر العربي. - الحربي، علي سعد (2002). أثر طريقة العصف الذهني في تنمية التفكير الناقد والتحصيل الدراسي لتلاميذ

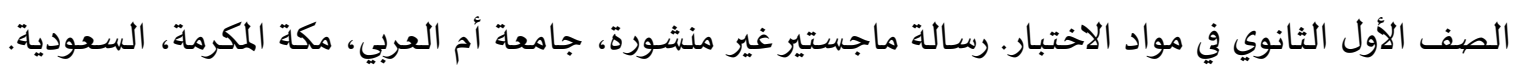

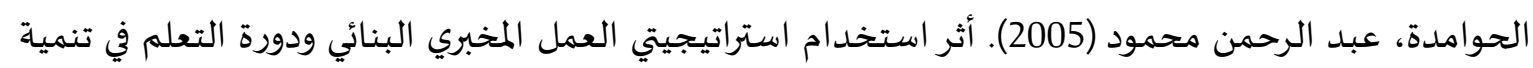

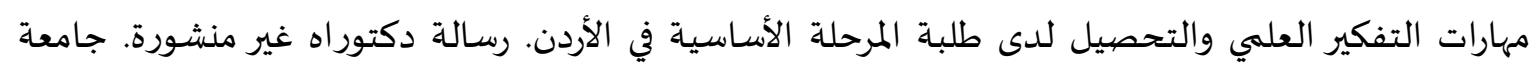
عمان العربية للدراسات العليا، الأردن.

- سعادة، جودت أحمد (2003). تدريس مهارات التفكير - مئات الأمثلة التطبيقية. عمان: دار الشروق.

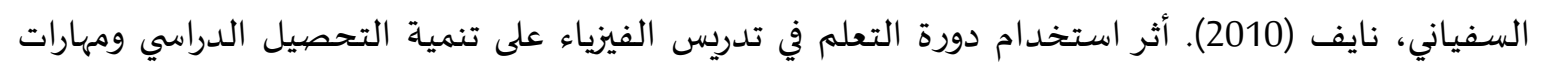
التفكير الابتكاري لدى طالب الصف الأول الثانوي. رسالة ماجستير غير منشورة، جامعة أم القرى: المملكة العربية السعودية. السويلمين، منذر (2019). فاعلية تدريس استراتيجية دورة التعلم الخماسية (5ES) على تنمية مهارات التفكير في العلوم لدى طالب الصف الثامن الأساسي في الأردن. مجلة الجامعة الإسلامية للدراسات التربوية والنفية دورة النعاسية، 20 .289-270:(2) - صالح، مدحت (2008). فعالية استخدام دورة التعلم فوق المعرفية في تنمية التفكير الناقد والتحصيل في مادة

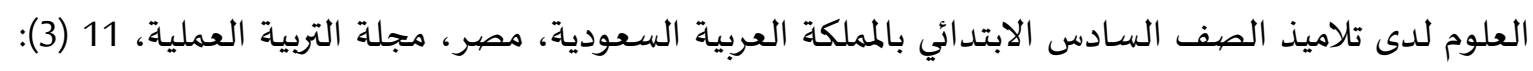

عبد العزيز، سعيد (2007). تعليم التفكير ومهاراته. عمان: دار الثقافة للنشروالتوزيع.

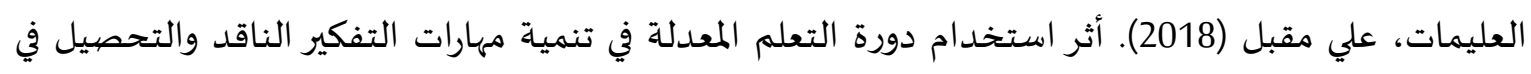

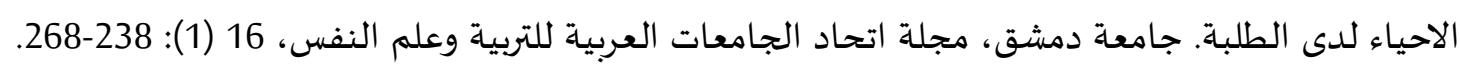

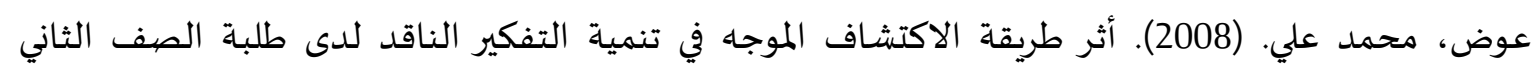

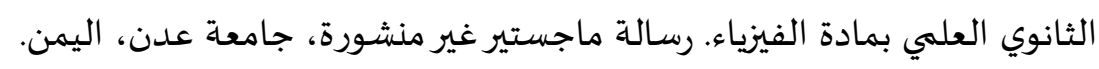

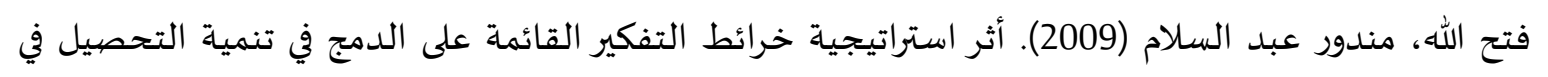

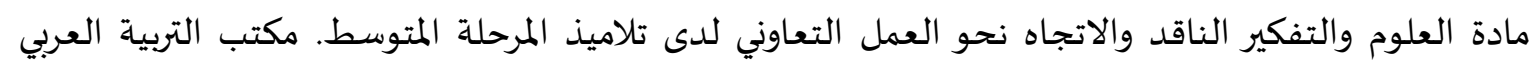

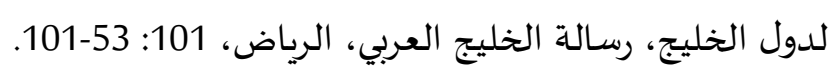


- الكندري، عيسى محمد (2005). أثر استخدام برنامج اثرائي في مادة العلوم في تنمية مهارات التفكير الناقد والتحصيل الدراسي لدى طلبة الصف السابع. رسالة ماجستير غير منشورة، جامعة الخليج العربي: البحرين. مكسيموس، داؤود وديع. (2003). البنائية في عمليتي تعليم وتعلم الرياضيات. المؤتمر العربي الثالث حول المدرخل المنظومي في التدريس والتعلم. مركز تطوير تدريس العلوم بالتعاون مع جامعة جرش الته الأهلية، الأردن.

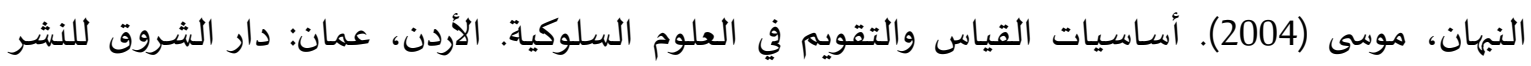
والتوزيع.

نوفل، محمد؛ وسعيفان، محمد (2011). دمج مهارات التفكير في المحتوى الدراسي. عمان: دار المسيرة للنشر والتوزيع والطباعة.

- الوادعي، شريفة (2017). أثر استخدام دورة التعلم الخماسي في تنمية مستوى مهارات التفكير الناقد في تدريس المفاهيم النحوية في اللغة العربية لدى طالبات الصف الأول الثانوي. مجلة التربية بجامعة الأزهر، 1 (175): $.839-806$ - اليتيم (2008) إلى الكشف عن أثر تكامل استراتيجيتين تستندان إلى فرضيات النظرية البنائية (استراتيجية دورة

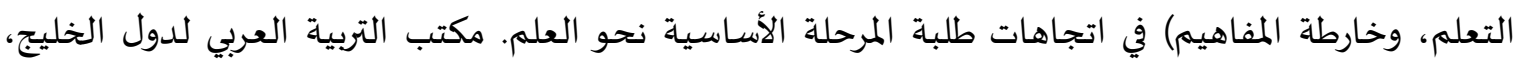
رسالة الخليج العربي، 29 (108): 61-101.

\section{ثانياً- المراجع بالإنجليزية:}

- Billings, R. L. (2001). Assessment of the learning cycle an inquiry based learning in high school Physics- Education. MS. Michigan state University. MAI 40/04, pp840.

- Cakiroglu, J. (2006). The effect of learning cycle approach on students' achievement in Science. Eurasian Journal of Educational Research, 22 (7): 61-73.

- Odom, A.L. \& Kelly, V.P. (2001). Integrating concept mapping and the learning cycle to teach diffusion and osmosis concepts to high school biology student. Science Education, 85, 615-635. 